OPEN ACCESS

Edited by: Valentina Fiorilli, University of Turin, Italy

Reviewed by:

Raffaella Balestrini,

Italian National Research Counci

(IPSP-CNR), Italy

Kalyan K. Mondal,

Indian Agricultural Research Institute

(ICAR), India

${ }^{*}$ Correspondence:

Hansong Dong

hsdong@njau.edu.cn

Specialty section:

This article was submitted to Plant Microbe Interactions,

a section of the journal

Frontiers in Plant Science

Received: 08 January 2019

Accepted: 26 April 2019

Published: 28 May 2019

Citation:

Zhang $L$, Chen $L$ and Dong $H$ (2019) Plant Aquaporins in Infection by and Immunity Against Pathogens A Critical Review.

Front. Plant Sci. 10:632 doi: 10.3389/fpls.2019.00632

\title{
Plant Aquaporins in Infection by and Immunity Against Pathogens - A Critical Review
}

\section{Liyuan Zhang ${ }^{1}$, Lei Chen ${ }^{1}$ and Hansong Dong ${ }^{1,2 *}$}

'Plant Immunity Research Group, National Key Laboratory of Crop Science, Department of Plant Pathology, Shandong Agricultural University, Tai'an, China, ${ }^{2}$ Plant Immunity Laboratory, Department of Plant Pathology, Nanjing Agricultural University, Nanjing, China

Plant aquaporins (AQPS) of the plasma membrane intrinsic protein (PIP) family face constant risk of hijack by pathogens aiming to infect plants. PIPs can also be involved in plant immunity against infection. This review will utilize two case studies to discuss biochemical and structural mechanisms that govern the functions of PIPs in the regulation of plant infection and immunity. The first example concerns the interaction between rice Oryza sativa and the bacterial blight pathogen Xanthomonas oryzae pv. oryzae (Xoo). To infect rice, Xoo uses the type III (T3) secretion system to secrete the proteic translocator Hpa1, and Hpa1 subsequently mediates the translocation of T3 effectors secreted by this system. Once shifted from bacteria into rice cells, effectors exert virulent or avirulent effects depending on the susceptibility of the rice varieties. The translocator function of Hpa1 requires cooperation with OsPIP1;3, the rice interactor of Hpa1. This role of OsPIP1;3 is related to regulatory models of effector translocation. The regulatory models have been proposed as, translocondependent delivery, translocon-independent pore formation, and effector endocytosis with membrane protein/lipid trafficking. The second case study includes the interaction of $\mathrm{Hpa} 1$ with the $\mathrm{H}_{2} \mathrm{O}_{2}$ transport channel AtPIP1;4, and the associated consequence for $\mathrm{H}_{2} \mathrm{O}_{2}$ signal transduction of immunity pathways in Arabidopsis thaliana, a non-host of $\mathrm{XoO} . \mathrm{H}_{2} \mathrm{O}_{2}$ is generated in the apoplast upon induction by a pathogen or microbial pattern. $\mathrm{H}_{2} \mathrm{O}_{2}$ from this source translocates quickly into Arabidopsis cells, where it interacts with pathways of intracellular immunity to confer plant resistance against diseases. To expedite $\mathrm{H}_{2} \mathrm{O}_{2}$ transport, AtPIP1;4 must adopt a specific conformation in a number of ways, including channel width extension through amino acid interactions and selectivity for $\mathrm{H}_{2} \mathrm{O}_{2}$ through amino acid protonation and tautomeric reactions. Both topics will reference relevant studies, conducted on other organisms and AQPs, to highlight possible mechanisms of T3 effector translocation currently under debate, and highlight the structural basis of AtPIP1;4 in $\mathrm{H}_{2} \mathrm{O}_{2}$ transport facilitated by gating and trafficking regulation.

Keywords: aquaporin, plasma membrane intrinsic protein, $\mathrm{H}_{2} \mathrm{O}_{2}$ transport, immunity signaling, translocon, type III effectors 


\section{INTRODUCTION}

Aquaporins (AQPs) are membrane-intrinsic proteins initially defined as water $\left(\mathrm{H}_{2} \mathrm{O}\right)$ transporting channels in all organisms and subsequently found to have many other substrate specificities (de Groot and Grubmuller, 2001; Maurel et al., 2008, 2015; Sutka et al., 2017), such as hydrogen peroxide $\left(\mathrm{H}_{2} \mathrm{O}_{2}\right.$; Tian et al., 2016). In plants, AQPs are classified into five major families (Chaumont et al., 2001; Maurel, 2007), including the plasma membrane intrinsic proteins (PIPs), tonoplast intrinsic proteins (TIPs), nodulin 26 like intrinsic proteins (NIPs), small basic intrinsic proteins (SIPs), and X intrinsic proteins (XIPs). The PIP family is further divided into the PIP1 subfamily made of PIP1;1 to PIP1;5 and the PIP2 subfamily consisting of PIP2;1 to PIP2;8 in most plant species (Maurel, 2007; Gomes et al., 2009; Laloux et al., 2018). While AQPs of the other four families function in substrate trafficking between organelles, PIPs are responsible for substrate transportation between the exterior and interior of cells (Maurel, 2007; Gomes et al., 2009; Kaldenhoff et al., 2014; Li et al., 2015; Bao, 2017).

Recently discovered functions of AQPs surpass the original "water channel" concept (Preston et al., 1992; Wudick et al., 2009; Heckwolf et al., 2011; Brown, 2017), and suggest implications in infection and immunity in both animals (Hara-Chikuma et al., 2015; Yang, 2017) and plants (Maurel et al., 2015; Wang F. et al., 2014; Zhang et al., 2018; Li et al., 2019). The functions of animal AQPs are no longer confined to substrate-transportbased processes such as urinary concentration and body fluid homeostasis (Brown, 2017), and are now known to include roles in various disease conditions and pathological states (Yang, 2017). Similarly, functional diversity - redundancy, overlapping, and extension beyond substrate transport - is a property of plant AQPs, especially PIPs (Ji and Dong, 2015b; Li et al., 2015; Zhang et al., 2018, 2019; Li et al., 2019). The functional scope of PIPs goes far beyond water relations or drought tolerance, extending to the subcellular transport of reactive oxygen species (ROS), including $\mathrm{H}_{2} \mathrm{O}_{2}$ (Tian et al., 2016; Smirnoff and Arnaud, 2019). $\mathrm{H}_{2} \mathrm{O}_{2}$ transport connects with signaling between the cell exterior and interior and between organelles, resulting in plant resistance to pathogen infection (Tian et al., 2016).

PIPs possess extracellular regions exposed to the outside environment (Maurel et al., 2015), and have potential to partake in plant responses to biotic and abiotic stresses. Here are several examples. Previous uses of induced resistance in crop protection (for example: Chen et al., 2008a,b; Fu et al., 2014; Wang F. et al., 2014) confirm the practical value of PIP-mediated immunity signal transduction (Tian et al., 2016). The correlation of PIP function in water transport with stress response results in promising strategies for improvement of plant tolerance to abiotic stresses, including drought (Balestrini et al., 2018). Drought tolerance in a variety of plant species is related to arbuscular mycorrhizal (AM) symbiosis, in which AM fungi (Rhizophagus spp.) show enhanced expression of AQP-encoding genes (Bárzana et al., 2014, 2015; Calvo-Polanco et al., 2016; Ruiz-Lozano et al., 2016; Sánchez-Romera et al., 2016; RuizLozano and Aroca, 2017). Surprisingly, the AM fungus R. clarus contributes its aquaglyceroporin (glycerol/water-transporting
$\mathrm{AQP}) \mathrm{RcAQP} 3$ to the mediation of long-distant polyphosphate translocation from the fungal vacuoles into cells of plant roots and leaves (Kikuchi et al., 2016). Genetic resources of plants, including the $\mathrm{AQP}$ transcriptome, can be used in responses to environmental cues, symbiotic microbes (AM fungi and rhizobia), and microbial pathogens (Desaki et al., 2018; Rey and Jacquet, 2018; Wang R. et al., 2018).

Due to their direct contact with the extracellular environment, PIPs risk being appropriated by plant pathogens to expedite infection (Zhang et al., 2018; Li et al., 2019). When infection is imminent, the real-time function of PIPs may switch from substrate transport to the regulation of plant responses to pathogens (Zhang et al., 2018; Li et al., 2019). This is either favorable or unfavorable to plant growth and development, depending on plant responses to pathogenicity determinants, called effectors, whose functions are subject to regulation of PIPs (Tian et al., 2016; Wang X. et al., 2018; Li et al., 2019; Zhang et al., 2019).

This review will summarize recent studies on the roles of PIPs in plant infection and immunity, and discuss the molecular, biochemical, and structural mechanisms involved. Discussion of infection will focus on type III (T3) effector translocation (T3ET) from Xanthomonas oryzae pv. oryzae (Xoo) into rice cells. Discussion of immunity will focus on the response of Arabidopsis to pathogens or pathogen-associated molecular patterns (PAMPs), also termed microbial patterns. This review will reference studies investigating AQPs in animals, microbes, and other plants to highlight the broad importance of PIP function, from substrate transport to infection and immunity in plants.

\section{THE CIRCUMSTANTIAL FUNCTION OF A PIP IN T3ET}

PIPs possess three extracellular regions that are exposed to the outside environment (Maurel et al., 2015). As a result, they are at a constant risk of being hijacked by pathogens attempting to infect plants, and inevitably partake in immunity against infection. Therefore, PIPs are required to extend their function from substrate transport to plant infection and immunity when the circumstances demand it. Emerging evidence suggests the implication of OsPIP1;3 in rice infection by Xoo (Zhang et al., 2018; Bian et al., 2019; Li et al., 2019). In this case, OsPIP1;3 functions with the bacterial hydrophilic protein Hpa1, which belongs to the harpin-group proteins secreted by the T3 secretion pathway of Gram-negative plant-pathogenic bacteria (Wei et al., 1992; Tejeda-Dominguez et al., 2017; Zhang et al., 2018; Li et al., 2019). Hpal produced by X. oryzae (Zhu et al., 2000; Chen et al., 2008a) is involved in the virulence of bacterial pathogens (Wang X. et al., 2018). Hpal modulates physiological and pathological processes in plants in association with PIPs (Sang et al., 2012; Li et al., 2013, 2014, 2015, 2019; Ji and Dong, 2015b; Zhang et al., 2018). The virulence role of Hpal is determined by its biochemical properties. Hpal is a one-domain harpin, which share a unitary hydrophilic "harpin" domain distinct from the enzymatic domain 
present in two-domain harpins (Kvitko et al., 2007; Choi et al., 2013; Ji and Dong, 2015b). Two-domain harpins have potential to associate with the bacterial periplasm or plant cell walls to facilitate assembly of the T3 secretion machinery (Mushegian et al., 1996; Koraimann, 2003; Zhang et al., 2008; Dik et al., 2017; Hausner et al., 2017). One-domain harpins, including Hpa1, target plasma membranes (PMs), where they serve as T3 translocators to mediate T3ET (Kvitko et al., 2007; Bocsanczy et al., 2008; Wang X. et al., 2018; Bian et al., 2019; Li et al., 2019).

In Xoo-infected rice plants, secreted Hpal translocates at least two transcription activator-like (TAL) effectors - AvrXa10 and PthXo1, which are also produced via the pathway (Wang X. et al., 2018). Translocated effectors exert virulent or avirulent effects depending on the susceptibility of the plant variety (Yang et al., 2006; Büttner, 2016; Schreiber et al., 2016; Schwartz et al., 2017; Zhang et al., 2018). The rice variety Nipponbare is susceptible to the TAL effector PthXo1 secreted by PXO99 ${ }^{\mathrm{A}}$, a well-studied Xoo strain (Yang et al., 2006; Wang X. et al., 2018; Zhang et al., 2018). To infect Nipponbare plants, $\mathrm{PXO} 99^{\mathrm{A}}$ secretes Hpal and delivers it to the cell surface, where Hpal interacts with OsPIP1;3 to facilitate the translocation of subsequently secreted PthXo1 into Nipponbare cells (Wang X. et al., 2018; Li et al., 2019). PthXo1 then induces virulence by activating its regulatory target the host susceptibility gene OsSWEET11 (Yang et al., 2006) in an OsPIP1;3-dependent manner (Zhang et al., 2018; Li et al., 2019). If the OsPIP1;3 gene is silenced by hairpin or knocked out by TALEN ${ }^{14}$, both PthXo1 translocation and OsSWEET11 expression incur concomitant impairments up to $70 \%$, highly alleviating virulence as a consequence (Zhang et al., 2018; Li et al., 2019). In contrast, both events acquire $>2$-fold enhancements if $O s P I P 1 ; 3$ is overexpressed, causing marked aggravations in virulence (Li et al., 2019).

AvrXa10 is an avirulent effector secreted by the Xoo strain PXO86, and induces immune responses in the resistant rice variety IRBB10 (Tian et al., 2014). The plant immunity is determined by the disease-resistant gene $\mathrm{Xa10}$, which is the target of AvrXa10 (Tian et al., 2014). Xa10 has two homologs in the Nipponbare genome - Xa10-Ni and $\mathrm{Xa23-Ni}$, both of which function similarly to confer immune responses in Nipponbare plants inoculated with recombinant PXO99 ${ }^{\mathrm{A}}$ strains that deliver the matching artificially designed TAL effectors (Wang et al., 2017). When avrXa10 is transferred from PXO86 into the $\mathrm{PXO}^{\mathrm{A}}$ genome, the resulting $\mathrm{PXO} 99^{\mathrm{A}} /$ avrXa10 recombinant delivers AvrXa10 in IRBB10 cells (Wang X. et al., 2018). Thereafter, AvrXa10 activates the disease resistant gene Xa10$\mathrm{Ni}$ to confer the plant resistance against the blight disease (Wang X. et al., 2018). The AvrXa10 translocation and Xa10-Ni activation incur concomitant impairments in plants inoculated with the hpal-deleted mutant; the absence of hpal markedly reduces the quantity of AvrXa10 translocation, decreasing the expression level of Xa10-Ni (Wang X. et al., 2018). The AvrXa10 translocation and $\mathrm{Xa10}-\mathrm{Ni}$ activation requires $\mathrm{OsPIP} 1 ; 3$, and both events are enhanced by $O s P I P 1 ; 3$ overexpression but inhibited by OsPIP1;3 silencing (Bian et al., 2019).

These findings demonstrate the important role of OsPIP1;3 in the translocation of T3 effectors, at least the TAL effectors PthXo1 and AvrXa10, from bacterial cells into the cytosol of rice cells. OsPIP1;3 functions either as a disease-susceptibility or resistance factor, depending on a virulent or avirulent function of the translocated effector.

\section{POTENTIAL MECHANISMS OF T3ET REGULATION}

Passages of proteic T3 effectors are 1.2-5.0 nanometers in width (Ji and Dong, 2015b; Guignot and Tran Van Nhieu, 2016), in contrast to PIP/AQP channels with an aperture around $3 \AA$, which is permeable to small substrates (Heckwolf et al., 2011; Li et al., 2015; Tian et al., 2016) but impossible for proteins to pass ( $\mathrm{Li}$ et al., 2019). Presumably, the role of OsPIP1;3 in T3ET complies with one of regulation models currently in debate (Domingues et al., 2016; Prasad et al., 2016; Santi-Rocca and Blanchard, 2017; Scheibner et al., 2017; Tejeda-Dominguez et al., 2017; Gaytán et al., 2018; Wagner et al., 2018; Shanmugam and Dalbey, 2019). Three models have been proposed as the canonical translocon-dependent delivery (Büttner, 2012; Figure 1 middle purple route) and the translocon-independent pore formation (Rüter et al., 2010; Figure 1 left black route) and endocytosis (Santi-Rocca and Blanchard, 2017; Figure 1 right red route). To date, studies on the three models have obtained empirical genetic evidence (Finsel and Hilbi, 2015; Domingues et al., 2016; Dong et al., 2016; Chakravarthy et al., 2017; Scheibner et al., 2017), but the structural basis of each model remains to be analyzed.

The first model of T3ET (Figure 1 middle purple route) was proposed to emphasize molecular interactions between T3 translocators and molecular interactions of T3 translocators with PM receptors (Büttner and Bonas, 2002; Büttner et al., 2008; Büttner, 2012; Ji and Dong, 2015b), either lipids (Haapalainen et al., 2011; Li et al., 2011), or proteins (Oh and Beer, 2007; Li et al., 2015; Adam et al., 2017). T3 translocators include one hydrophilic protein, such as Hpal from xanthomonads - bacteria in the Xanthomonas genus (Zhu et al., 2000; Chen et al., 2008a; Wang X. et al., 2018), and two hydrophobic proteins (Büttner et al., 2008; Ji and Dong, 2015b), such as HrpF from the same bacteria (Büttner et al., 2002; Li et al., 2011; Hausner et al., 2017). Recognition of the hydrophilic translocator by a component of the PM composition is the first step towards translocon assembly (Goure et al., 2004; Mueller et al., 2008; Sawa et al., 2014). Then, the translocon is finalized by the binding of lipids to hydrophobic translocators (Büttner et al., 2008; Büttner, 2012; Ji and Dong, 2015b). A completed translocon possesses an inner conduit that opens into a target cell and accommodates bacterial effector translocation (Büttner et al., 2008; Chatterjee et al., 2013; Ji and Dong, 2015b; Büttner, 2016).

Although there is no evidence so far to verify the T3 translocon assembly, many studies suggest the involvement of T3 translocators in effector translocation from animal- and plantpathogenic bacteria into cells of their corresponding eukaryotic hosts (summarized in Scheibner et al., 2017). Mounting evidence indicates the engagement of PM phospholipids in T3ET, especially phosphatidylinositol phosphates PI(n)Pn (Lee et al., 2001a,b; Büttner et al., 2002; Weber et al., 2006; Hubber and Roy, 2010; Li et al., 2011; Finsel and Hilbi, 2015; Dong et al., 2016). For T3ET 


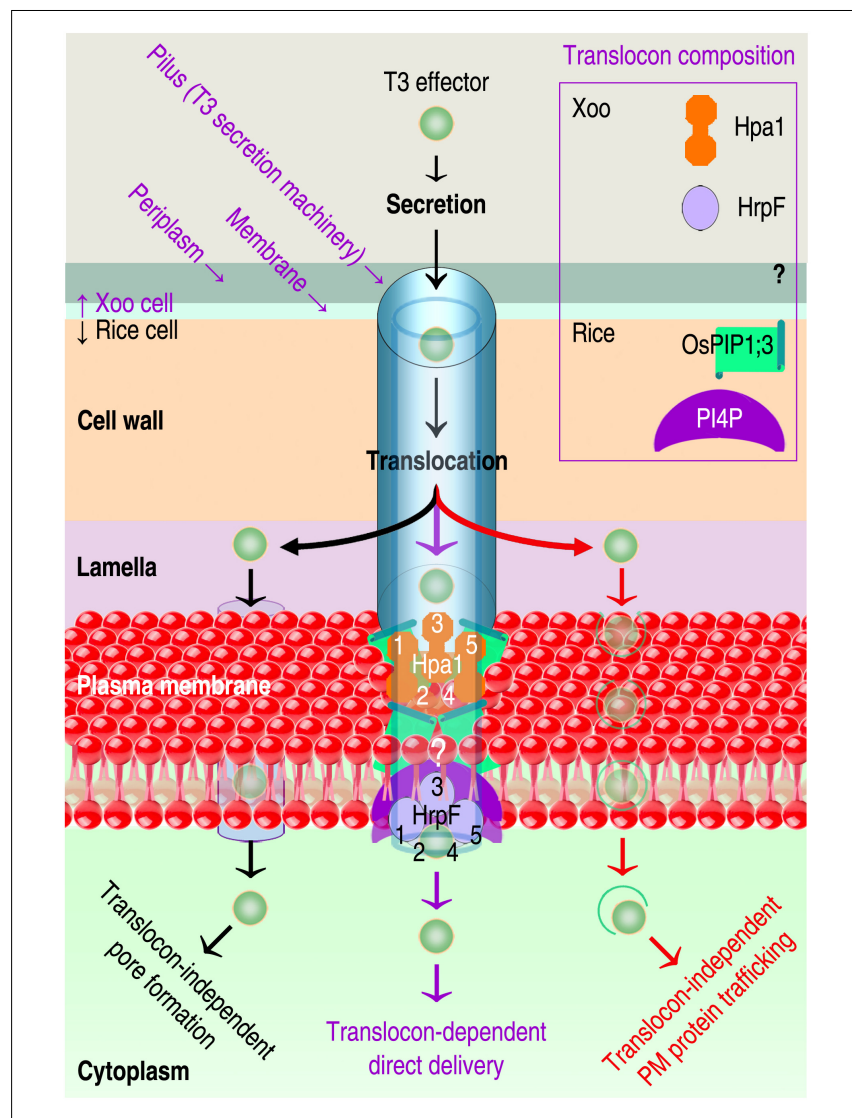

FIGURE 1 | Hypothetic routes of T3ET using Xoo as an example. Effector translocation may use the left black route (Rüter et al., 2010; Scheibner et al., 2017) or the right red pathway (Lu et al., 2007; Santi-Rocca and Blanchard, 2017) according to recently proposed models. In a previously proposed model, T3ET occurs via the translocon (the middle purple route) hypothetically assembled by interactions between translocators, and their receptors in eukaryotic PMs (Büttner, 2012; Ji and Dong, 2015b). Three translocators have been identified in animal-pathogenic bacteria, but the number of T3 translocator remains unknown in plant-pathogenic bacteria including Xoo. In Xoo, the hydrophilic protein Hpa1 (Wang X. et al., 2018) and the hydrophobic protein HrpF (Büttner et al., 2002; Li et al., 2011) were determined to function as T3 translocators, but whether the third translocator exists is unclear (question marks). Regarding molecular interactions during the translocon assembly, OsPIP1;3 has been verified to interact with $\mathrm{Hpa} 1$ at rice PMs to expedite the translocation of TAL effectors AvrXa10 and PthXo1 (Zhang et al., 2018; Li et al., 2019). In the cartoon, numbers 1 through 5 refer to the order of the translocator in self oligomerization to form the homogenous complex, which is assumed to be consisting of 5 or 8 monomers (Mueller et al., 2008). In vitro assays indicated HrpF binding to lipids (Büttner et al., 2002; Li et al., 2011), such as PI4P, but no evidence was available to demonstrate the lipid binding at plant PMs and the subsequent effect on T3 effector translocation.

from xanthomonads, lipids in the plant PM associates with the bacterial hydrophobic T3 translocator HrpF (Büttner et al., 2002; Li et al., 2011). HrpF was the first reported T3 translocator and is regarded as a marker of T3 translocon in xanthomonads (Büttner et al., 2002; Scheibner et al., 2017). HrpF is highly conserved in xanthomonads (Sugio et al., 2005) and has been shown to mediate the translocation of AvrBs3 from $X$. campestris pv. vesicatoria $(X c v)$ - the bacterial spot pathogen of pepper (Büttner et al., 2002;
Noël et al., 2002), and from X. oryzae pv. oryzicola - the pathogen that causes bacterial leaf streak in rice (Li et al., 2011). Evidence is further provided by our demonstrations that the hydrophilic T3 translocator Hpal of Xoo interacts with OsPIP1;3 at rice PMs to expedite translocation of TAL effectors PthXo1 and AvrXa10 from Xoo cells into the cytosol of rice cells (Zhang et al., 2018; Bian et al., 2019; Li et al., 2019).

The second model of T3ET (Figure $\mathbf{1}$ left black pathway) is the translocon-independent pore formation by bacterial effectors characteristic of cell-penetrating peptide (RPP; Scharnert et al., 2013; Rüter and Schmidt, 2017). Pore forming in eukaryotic PMs is momentary, occurs quickly upon recognition of bacterial effectors, and is regulated by membrane repair mechanisms (Scharnert et al., 2013). RPPs are either autonomously transported across the membrane or delivered by endocytosis (Wang F. et al., 2014). Autonomous translocation was found with the T3 effector YopM from Yersinia enterocolitica (Rüter et al., 2010). The YopM sequence contains two N-terminal $\alpha$-helices, which determines the interaction with eukaryotic PMs (Li et al., 2019), and two putative nuclear localization signals at the C-terminus (Benabdillah et al., 2004). Therefore, YopM can be translocated directly into the cytosol of target cells and further transported into the nucleus via vesicle trafficking (Skrzypek et al., 1998).

Little is known about the translocon-independent translocation of T3 effectors from plant-pathogenic bacteria except for the TAL effector AvrBs3 from Xcv. Preliminary infection experiments with $X c v$ translocon mutants and endocytosis inhibitors deny a contribution of endocytosis to the delivery of AvrBs3 (Scheibner et al., 2017). A possible route for AvrBs3 translocation from the translocon mutants is a direct transportation through pore formation. The pore could be proteolipidic (Gilbert et al., 2014) and could be generated by means of proteic and lipidic constituents, which are required for the translocation of T3 effectors from xanthomonads (Büttner et al., 2002; Li et al., 2011, 2019). However, the efficiency of AvrBs3 translocation from the translocon mutants is much lower than that from the WT strain, indicating that the transloconindependent route is used in the absence of alternative.

The third model of T3ET (Figure 1 left black pathway) was recently proposed to emphasize the effector endocytosis through direct interaction with receptors situated in eukaryotic PMs (Domingues et al., 2016). The molecular interaction may trigger the membrane trafficking mechanism (Allgood and Neunuebel, 2018) either by endoplasmic reticulum (ER) or vesicles (Wudick et al., 2015), providing a potential scheme for bacterial effector endocytosis (Figure 2). Protein and lipid trafficking via ER is universal (Cybulsky, 2017; Obacz et al., 2017), and vesicle-mediated PIP trafficking has been elucidated in roots of Arabidopsis following treatment with $\mathrm{H}_{2} \mathrm{O}_{2}$ (Wudick et al., 2015). The treatment induces AtPIP2;1 accumulation in the late endosomal compartments, and increases stability of the PIP and its homologs in the cytoplasm (Wudick et al., 2015). Like AtPIP1;4 (Li et al., 2015, 2019), AtPIP2;1 also is an $\mathrm{H}_{2} \mathrm{O} / \mathrm{H}_{2} \mathrm{O}_{2} / \mathrm{CO}_{2}$ triple channel (Heckwolf et al., 2011; Rodrigues et al., 2017), but no study shows whether or not AtPIP2;1 resembles AtPIP1;4 to regulate bacterial effector translocation. 


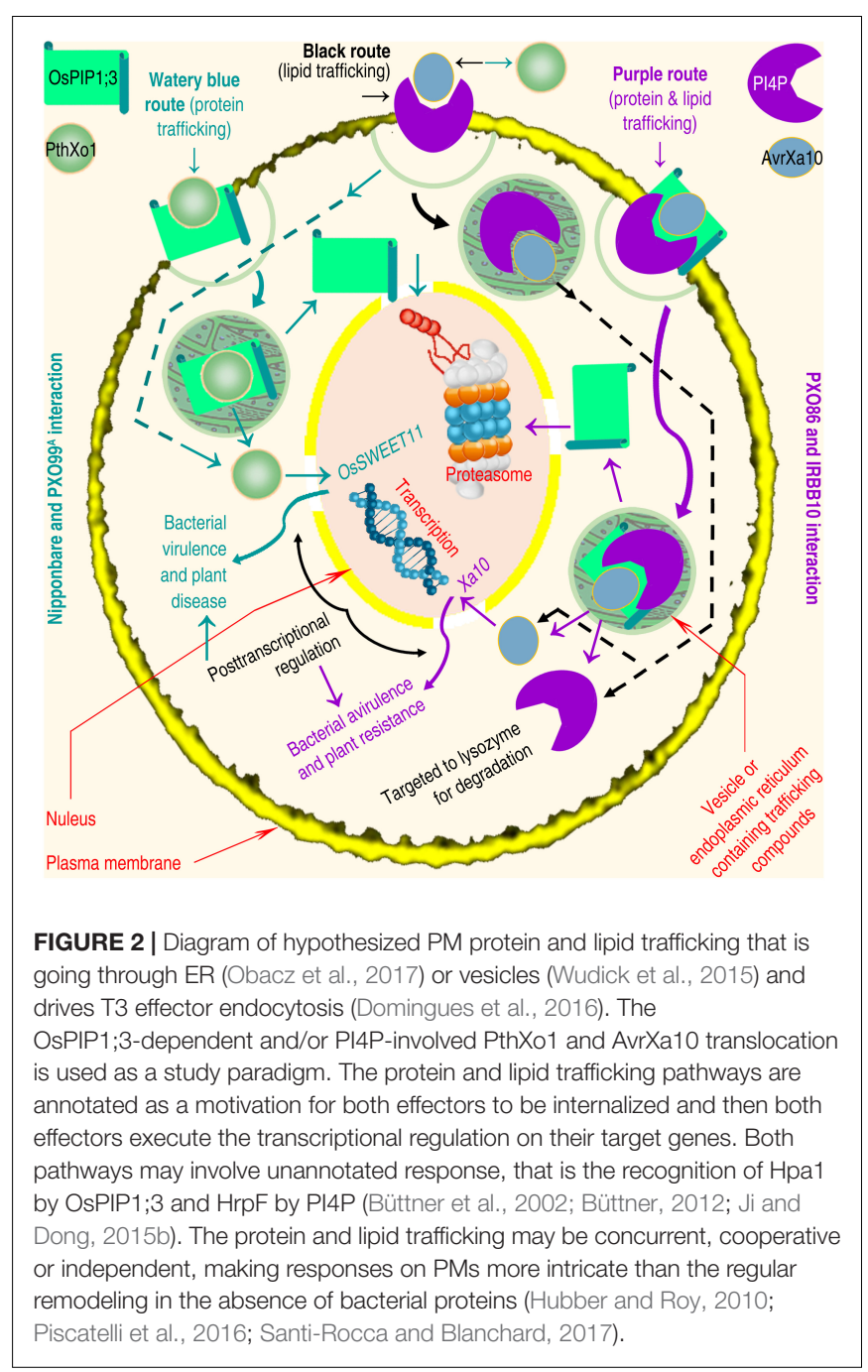

It is deserved of studying whether multiple substrate specificities of a PIP enable it to accommodate bacterial effectors.

There are two examples indicating the possibility that T3 effectors of plant-pathogenic bacteria are translocated along with membrane trafficking. One is the T3 effector HopZ1a of Pseudomonas syringae pv. syringae, bacterial pathogen of many plants. HopZ1a, HopZ1b, and HopZ1c are allelic forms, constitute the HopZ1 family of $P$. syringae T3 secretion system, and share a consensus myristoylation site required for membrane localization (Zhou et al., 2009). HopZ1a is an acetyltransferase, is activated by the eukaryotic co-factor phytic acid, and turns to acetylate itself and tubulin. Tubulin acetylation causes a decrease in microtubule networks, disrupts the secretory pathway, and suppresses cell wall-associated defense in plants (Lee et al., 2012). The defense is subject to complex regulatory networks, which involve vesicle trafficking linked to microtubules (Lehman et al., 2017). The other example is the T3 effector HopM1 of $P$. syringae pv. tomato. To infect tomato plants, the bacteria secrets HopM1, and delivers it into the plant PM-derived transGolgi network/early endosome (Nomura et al., 2011), suggesting a role of vesicle trafficking in HopM1 translocation.
The involvement of AQPs in T3 effector endocytosis can be speculated from independent studies summarized below. The trafficking of animal AQPs towards the cell interior is triggered by the AQP binding to a different protein (Zelazny et al., 2009; Ji and Dong, 2015a), such as vasopressin (Kamsteeg et al., 2006), or heat shock protein HSP70 (Lu et al., 2007). Nevertheless, molecular interactions at the PM transiently affect PM integrity (Laliberté and Sanfaçon, 2010; Guignot and Tran Van Nhieu, 2016; Santi-Rocca and Blanchard, 2017), which may extricate and internalize PM-associated proteins to accommodate foreign molecules like T3 effectors. It is possible that AvrBs3 and PthXo1 use this mechanism to enter rice cells together with OsPIP1;3 trafficking (Figure 2). Both effectors may be internalized through trafficking of OsPIP1;3 en route to degradation by the proteasome (Hirano et al., 2003; Centrone et al., 2017) or the autophagosome (Khositseth et al., 2017). This mode of trafficking and degradation has been shown to regulate animal AQP turnover (Khositseth et al., 2017; Shen et al., 2019) and may also apply to plant AQPs. It is necessary to verify whether OsPIP1;3, or any other PIPs, can interact with any of the bacterial effectors, in the absence of Hpa1, to cause the PIP and effector internalization.

How could PM binding lead to endocytosis of bacterial effectors? The binding of effectors or translocators to the PM induces transient damage to the integrity and function of PM compositions, providing an abnormal pathway for bacterial effector translocation (Guignot and Tran Van Nhieu, 2016). In addition to $\mathrm{T} 3$, other secretion systems, such as T4, may be involved also (Domingues et al., 2016). Salmonella enterica serovars are intracellular facultative pathogens with a wide host range, and cause serious diseases including typhoid fever and cholera in humans (Domingues et al., 2016; Piscatelli et al., 2016). About 40 different T3 effectors confer differential virulence to different serovars. For infection, Salmonella bacteria establish a bacteria-containing vacuole (BVC), induce tubules, and then deliver the $\mathrm{T} 3$ effector SteA onto the $\mathrm{BCV}$ and tubules. In both structures, SteA specifically interacts with PI4P to move into host cells (Domingues et al., 2016). Legionella pneumophila, the pathogen responsible for Legionnaire' disease, creates BCV through effectors secreted by the Dot/Icm T4 system (Finsel and Hilbi, 2015). In BCV, the pathogen hijacks host PM trafficking to induce BCV maturation (Hubber and Roy, 2010). The BCV membrane mainly contains PI4P (Weber et al., 2006; Finsel and Hilbi, 2015), which is important for anchoring many Dot/Icm effectors onto BCV (Dong et al., 2016). The T4 effector LepBd of L. pneumophila is a phosphatase (PP), and specifically converts PI3P into $\mathrm{PI}(3,4) \mathrm{P}_{2}$. $\mathrm{PI}(3,4) \mathrm{P}_{2}$ is efficiently hydrolyzed into PI4P (Dong et al., 2016), which may be used to replenish the PI4P stock of BCV. This mechanism is also employed by the T3 effector SopB of cholera pathogen S. enterica serovar Typhimurium. Like the T4 effector LepBd of L. pneumophila, the T3 effector SopB of Typhimurium is also a PP, but possesses both 4-PP and 5-PP activities. This dual enzymatic function is essential for the formation of BCV membrane ruffles and subsequent bacterial invasion. The 5-PP activity of SopB is assumed to generate $\mathrm{PI}(3,4) \mathrm{P}_{2}$, which is then recruited by sorting nexin 9 (SNX9), an actin-modulating protein. The 4-PP activity converts $\mathrm{PI}(3,4) \mathrm{P}_{2}$ to $\mathrm{PI} 3 \mathrm{P}$. Alone, neither activity is sufficient for 
membrane ruffling. Instead, combined 4-PP and 5-PP activities induce SNX9-mediated membrane ruffling and bacterial invasion (Dong et al., 2016).

The three models of T3ET may be chosen to use circumstantially by bacteria with genetic variations in the $\mathrm{T} 3$ repertoire. For example, the translocon-dependent mechanism guarantees efficient translocation of AvrBs3 from the wild-type $X c v$ strain (Büttner et al., 2002), in contrast to insufficient translocation from the bacterial translocon mutants in a translocon-independent manner (Scheibner et al., 2017). An early report stated that the carboxy (C)-terminal region of $\mathrm{HrpF}$ is essential for the entry of $\mathrm{Xcv}$ AvrBs3 into plant cells, whereas the nitrogen $(\mathrm{N})$-terminal contains a secretion signal and has no effect on effector translocation (Büttner et al., 2002). This suggests that xanthomonads T3ET occurs in a translocondependent manner. By contrast, a recent report proposed a translocon-independent pathway (Scheibner et al., 2017). The $\mathrm{N}$-terminal 10 and 50 amino acids are required for $\mathrm{T} 3$ secretion and AvrBs3 translocation, respectively. Additional signals in the $\mathrm{N}$-terminal 30 amino acids and the region between amino acids 64 and 152 promote AvrBs3 translocation. AvrBs3 translocation occurs in the absence of the T3 secretion chaperon $\mathrm{HpaB}$, and in the absence of HrpF, which is a predicted component of the T3 translocon assembly. The authors suggested that the delivery of AvrBs3 begins during the early stages of infection, before the activation of $\mathrm{HpaB}$ or translocon integration into the plant PM (Scheibner et al., 2017). It is more likely that a different translocator, present in reserve and lacking function when the bacteria possesses a workable HrpF, is employed when $\mathrm{HrpF}$ loses function or is removed from the bacterial proteome.

\section{A CYTOLOGICAL GAP BETWEEN $\mathrm{H}_{2} \mathrm{O}_{2}$ SIGNALING AND IMMUNITY PATHWAYS}

$\mathrm{H}_{2} \mathrm{O}_{2}$ is stable compared with other ROS molecules such as the superoxide anion $\mathrm{O}_{2}^{-}$and hydroxyl radical $\mathrm{OH}^{-}$. In plants, $\mathrm{H}_{2} \mathrm{O}_{2}$ is produced by the enzymatic activities via multiple biochemical mechanisms (Smirnoff and Arnaud, 2019). These mechanisms include electron leakage from the electron transport chain in chloroplasts and mitochondria, the activity of peroxisomal oxidases and peroxidases in cytoplasm or plant cell walls, as well as the activity of NADPH oxidases (NOXs) in the PM (Smirnoff and Arnaud, 2019). The rapid production of ROS, especially $\mathrm{H}_{2} \mathrm{O}_{2}$, indicates the successful recognition of pathogen infection and molecular patterns (Alvarez et al., 1998; Torres, 2009). Well-known examples of pathogenic patterns include invariant microbial epitopes, such as fungal chitin (Kaku et al., 2006) and bacterial flagellin (Zipfel et al., 2004) and harpin proteins (Sang et al., 2012; Choi et al., 2013). These pattern molecules can be recognized by pattern receptors within the PM, which induce immune responses, including $\mathrm{H}_{2} \mathrm{O}_{2}$ production, in plants (Levine et al., 1994; Ausubel, 2005; Galletti et al., 2011).

The production of $\mathrm{H}_{2} \mathrm{O}_{2}$ is typically apoplastic, resulting mainly from the enzymatic activity of NOXs located in PMs (Sagi and Fluhr, 2006; Kärkönen and Kuchitsu, 2015; Smirnoff and Arnaud, 2019). Then, there is crosstalk between $\mathrm{H}_{2} \mathrm{O}_{2}$ and immunity pathways, such as systemic acquired resistance (SAR) and pattern-triggered immunity (PTI) to regulate plant disease resistance (Torres, 2009). SAR is characteristic of the induced expression of pathogenesis-related (PR) genes, typically $P R-1$ and $P R-2$, under the regulation of non-inducer of $P R$ genes-1 (NPR1) (Cao et al., 1997; Kim et al., 2011). NPR1 functions through conformational changes under cytoplasmic redox conditions (Tada et al., 2008) and through proteasome-mediated turnover in the nucleus (Spoel et al., 2009). The PTI pathway activates a cytoplasmic MAPK cascade (Asai et al., 2002), including a branch in which MPK3 and MPK6 phosphorylate different substrates (Bigeard et al., 2015; Pitzschke, 2015) to activate immune responses, including $\mathrm{H}_{2} \mathrm{O}_{2}$ and callose production (Bethke et al., 2012; Daudi et al., 2012). Callose is a $\beta$-1,3-glucan synthesized by glucan synthase-like (GSL) enzymes, with GSL5 playing a critical role in cellular immune responses (Lü et al., 2011). Therefore, both the SAR and PTI pathways comprise pivotal tiers of intracellular responses in the crosstalk with $\mathrm{H}_{2} \mathrm{O}_{2}$ produced in the apoplast (Sagi and Fluhr, 2006). It is clear that a cytological gap exists between $\mathrm{H}_{2} \mathrm{O}_{2}$ generation and functional performance. In fact, it remains unclear for a long time how apoplastic $\mathrm{H}_{2} \mathrm{O}_{2}$ penetrates plant PMs to enter the cytoplasm and regulate immunity.

\section{PIP-MEDIATED $\mathrm{H}_{2} \mathrm{O}_{2}$ TRANSPORT AND ITS IMMUNOLOGICAL IMPORTANCE}

Hpa1, applied to plants or produced in transgenic plants, functions as a bacterial pattern to activate the PTI and SAR pathways (Tian et al., 2016). Both pathways are activated by the generation of ROS, especially $\mathrm{H}_{2} \mathrm{O}_{2}$, in plant apoplasts. In Arabidopsis, inoculation with the bacterial pathogen Pseudomonas syringae pv. tomato or treatment with bacterial patterns, including Hpal and the flagellin functional fragment flg22, induce $\mathrm{H}_{2} \mathrm{O}_{2}$ generation in the apoplast. This $\mathrm{H}_{2} \mathrm{O}_{2}$ moves quickly into the cytoplasm, where $\mathrm{H}_{2} \mathrm{O}_{2}$ associates with PTI and SAR signal transduction. AtPIP1;4 serves as a $\mathrm{H}_{2} \mathrm{O}_{2}$ transport channel to facilitate apoplastic $\mathrm{H}_{2} \mathrm{O}_{2}$ import into the cytoplasm (Figure 3A), bridging the cytological gap in immunity signaling cascades (Tian et al., 2016).

This finding validates the hypothesis that $\mathrm{H}_{2} \mathrm{O}_{2}$ transport across a biomembrane is mediated by particular AQP isoforms in addition to certain membrane lipids (Bienert et al., 2006, 2007; Bienert and Chaumont, 2014; Aguayo et al., 2015). AQPs are transmembrane channels essential for the transport of $\mathrm{H}_{2} \mathrm{O}$, $\mathrm{H}_{2} \mathrm{O}_{2}$, and other small substrates in all living cells (Maurel, 2007; Gomes et al., 2009). In this way, AQPs can modulate many physiological and/or pathological processes (Maurel, 2007; Ji and Dong, 2015a,b; Li et al., 2019; Pawłowicz and Masajada, 2019; Zhang et al., 2019). In most plant species, five major families of AQPs exist. The PIP family has 11 members, PIP1;1-5 and PIP2;1-8 (Gomes et al., 2009; Abascal et al., 2014; Maurel et al., 2015). These are believed to mediate the transport of different substrates across plant PMs in an overlapping or redundant substrate-specific manner (Maurel, 2007; Péret et al., 2012, 2013; Prado et al., 2013). To date, five AtPIP isoforms (2;1, 2;2, 2;4, 2;5, 
A

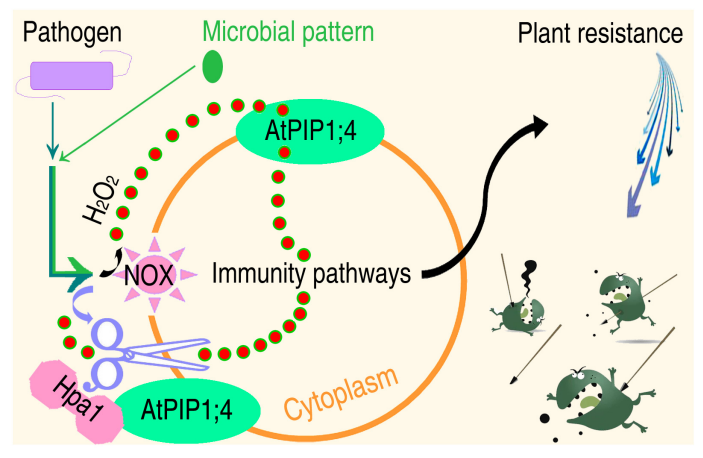

B

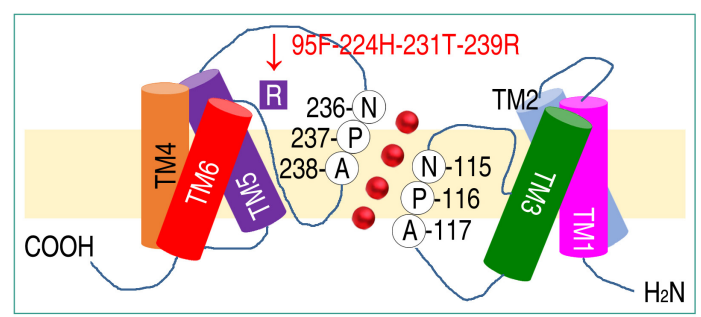

C

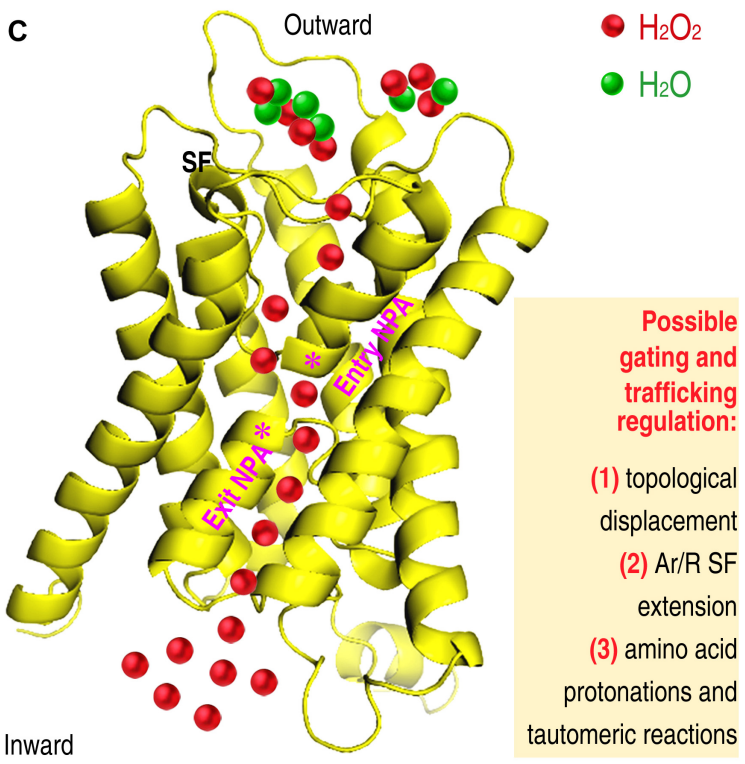

FIGURE 3 | Crosstalk of AtPIP1;4-mediated $\mathrm{H}_{2} \mathrm{O}_{2}$ transport with the intracellular immunity pathways and predicted mechanisms by which AtPIP1;4 fulfills the substrate transport function. (A) Plant sensing of a pathogen or microbial pattern not only is an essential step of apoplastic generation and cytoplasmic import of $\mathrm{H}_{2} \mathrm{O}_{2}$, but also induces damages to the PM integrity (Guignot and Tran Van Nhieu, 2016). Impairment of the PM integrity is likely to provide an abnormal channel, which is wider than the normal conduit, and capable of accommodating substrates larger than $\mathrm{H}_{2} \mathrm{O}$. (B) Hypothetic determinants of AtPIP1;4 conformation for $\mathrm{H}_{2} \mathrm{O}_{2}$ transport include amino acid compositions and locations in the NPA and SF regions. (C) Gating and trafficking regulation of the AtPIP1;4 channel for $\mathrm{H}_{2} \mathrm{O}_{2}$ transport across plant PMs (left) may be subject to the annotated factors (right). The 3D-structure of AtPIP1;4 was predicted by using the PHYRE2 (Protein Homology/analogy Recognition Engine $V$ 2.0) program

(http://www.sbg.bio.ic.ac.uk/phyre2/html/page.cgi?id = index). The diagrammatic transport of $\mathrm{H}_{2} \mathrm{O}_{2}$ over $\mathrm{H}_{2} \mathrm{O}$ is a surmise, predicted to occur by the combined mechanisms indicated on right. and 2;7) are assumed to mediate $\mathrm{H}_{2} \mathrm{O}_{2}$ transport in engineered yeast cells (Bienert and Chaumont, 2014). The de novo expression of these PIPs can increase $\mathrm{H}_{2} \mathrm{O}_{2}$ sensitivity and decrease the viability of yeast (Dynowski et al., 2008; Hooijmaijers et al., 2012). Based on incomplete literature search, not all PIPs whose expression increases $\mathrm{H}_{2} \mathrm{O}_{2}$ sensitivity and decreases the viability of yeast have been verified for the $\mathrm{H}_{2} \mathrm{O}_{2}$ transporting function. AtPIP2;1 was determined to increase $\mathrm{H}_{2} \mathrm{O}_{2}$ uptake by yeast cells (Dynowski et al., 2008; Bienert and Chaumont, 2014) and by Arabidopsis guard cells (Rodrigues et al., 2017). AtPIP1;4 has been shown to function in $\mathrm{H}_{2} \mathrm{O}_{2}$ transport from the apoplast into the cytoplasm of Arabidopsis (Tian et al., 2016). Many works are required to test in planta function of the AQP candidates in $\mathrm{H}_{2} \mathrm{O}_{2}$ translocation.

\section{CONSERVATIVE AQP FUNCTION FOR $\mathrm{H}_{2} \mathrm{O}_{2}$ TRANSPORT}

AtPIP1;4 was determined to have triple substrate specificities ( $\mathrm{Li}$ et al., 2015; Tian et al., 2016). In addition to transporting $\mathrm{H}_{2} \mathrm{O}_{2}$ (Tian et al., 2016), AtPIP1;4 partakes in the cellular hydraulic conductance $\left(\mathrm{P}_{\mathrm{f}}\right)$ of roots, and in mesophyll conductance of $\mathrm{CO}_{2}$ $\left(g_{\mathrm{m}}\right)$; however, it does not affect stomatal $\mathrm{CO}_{2}$ conductance $\left(g_{\mathrm{s}}\right)$ or $\mathrm{P}_{\mathrm{f}}$ in leaves (Li et al., 2015). The interaction of AtPIP1;4 with Hpal at Arabidopsis PMs promotes substrate transport, increasing the net photosynthesis rate $\left(A_{\mathrm{N}}\right)$, while $\mathrm{P}_{\mathrm{f}}$ is also increased in leaves and roots (Li et al., 2015). Therefore, a PIP can alter its physiological functions or effect extents in response to plant pathogens or bacterial patterns.

The function of AtPIP1;4 in immunity is an extension of its primary roles in substrate transport, which was initially assigned to AQPs in mammals (Preston and Agre, 1991) and subsequently in plants (Maurel et al., 1993). The functional extension of AtPIP1;4 has biological importance for at least two reasons. First, AtPIP1;4-dependent SAR responses induced by bacterial pathogens effectively repress pathogen virulence (Tian et al., 2016; Figure 3A). In this case, pathogen-associated repressors of plant immunity (Oh and Collmer, 2005; Zhang et al., 2007; Guo et al., 2009) may be inhibited, or their immunity-repressing functions may be counteracted by the role of AtPIP1;4 in $\mathrm{H}_{2} \mathrm{O}_{2}$ translocation, which is linked to the immunity pathway. Second, AtPIP1;4 is an integral component of PTI in response to typical patterns, with conserved microbial cell-surface composition, i.e., flagellin (Zipfel et al., 2004) and chitin (Kaku et al., 2006). Despite their different biochemical nature, both patterns require AtPIP1;4 to induce PTI responses, except in the absence of induced MPK6 expression (Tian et al., 2016). This is consistent with previous findings that the MAPK cascade diverges at MPK3 and MPK6 (Asai et al., 2002; Bigeard et al., 2015) to regulate distinct substrates in response to different patterns (Galletti et al., 2011; Pitzschke, 2015). Moreover, the induction of MPK3 expression represents a circuit of the MAPK cascade in response to $\mathrm{H}_{2} \mathrm{O}_{2}$ (Gudesblat et al., 2007). These sets of information suggest that AtPIP1;4 plays a prominent role in immunity signaling by mediating apoplastic $\mathrm{H}_{2} \mathrm{O}_{2}$ translocation into plant cells. 
AQP-mediated $\mathrm{H}_{2} \mathrm{O}_{2}$ transport in immune signaling also occurs in mammals. Among 13 AQPs, AQP3 is a $\mathrm{H}_{2} \mathrm{O}_{2}$ transport channel (Miller et al., 2010). AQP3-mediated $\mathrm{H}_{2} \mathrm{O}_{2}$ transport is associated with necrosis factor- $\kappa \mathrm{B}$ (NF$\kappa \mathrm{B})$ signaling in keratinocytes, and in the pathogenesis of psoriasis in response to cytokine regulation (Hara-Chikuma et al., 2015). The induction of psoriasis by cytokines, NF$\kappa \mathrm{B}$ activation, and intracellular $\mathrm{H}_{2} \mathrm{O}_{2}$ accumulation are concomitantly reduced in AQP3-knockout mice. In primary keratinocyte cultures, $\mathrm{H}_{2} \mathrm{O}_{2}$ is generated by membraneassociated NOX2 in response to TNF- $\alpha$, and moves into intracellular spaces. Cellular import of $\mathrm{H}_{2} \mathrm{O}_{2}$ is facilitated by $\mathrm{AQP} 3$ and is required for NF- $\mathrm{B}$ activation under $\mathrm{PP} 2 \mathrm{~A}$ regulation. Since AQP3 associates with NOX2 at PMs, this interplay may constitute $\mathrm{H}_{2} \mathrm{O}_{2}$-mediated signaling in response to TNF- $\alpha$ stimulation (Hara-Chikuma et al., 2015). Moreover, under oxidative stress, AQP3-mediated $\mathrm{H}_{2} \mathrm{O}_{2}$ transport attenuates apoptosis by regulating the P38 MAPK pathway (Xu et al., 2018; He and Yang, 2019). Based on these findings, and those regarding PIPs, cytoplasmic import across the PM can reduce the cytological distance for $\mathrm{H}_{2} \mathrm{O}_{2}$ generation, and functional performance (Bienert et al., 2006; Sang et al., 2012; Tian et al., 2016). Apocytoplastic signaling is conserved in plants and animals.

\section{AQP STRUCTURE FOR $\mathrm{H}_{2} \mathrm{O}$ TRANSPORT}

It is unclear how different AQPs function in the transport of corresponding substrates, and how an AQP, such as AtPIP1;4 (Li et al., 2015; Tian et al., 2016), can function as a triple substrate transport conduit. One hypothesis is that structural details allow for differences in selectivity and modes of regulation (Kreida and Törnroth-Horsefield, 2015). Regarding $\mathrm{H}_{2} \mathrm{O}_{2}$ transport, the structures of AQP/PIP channels have not been studied, but can be inferred from information on structures of AQPs that function as water channels.

Plant aquaporins are predominant channels of $\mathrm{H}_{2} \mathrm{O}$ transport between the outside and inside of the cell, and between intracellular organelles (Huang et al., 2017). Although cotransporters and uniporters have been implicated in water homeostasis, AQPs have been accepted as intramolecular channels for the transmembrane movement of $\mathrm{H}_{2} \mathrm{O}$ down an osmotic gradient (Maurel et al., 2015; Huang et al., 2017; Yang, 2017; Pawłowicz et al., 2018). $\mathrm{H}_{2} \mathrm{O}$ transport by AQPs is determined by their three-dimensional structure.

Structural studies have characterized AQPs as homotetramers, which are integrated into the membrane with conserved configurations (Fu et al., 2000; Sui et al., 2001; TörnrothHorsefield et al., 2006; Horsefield et al., 2008; Eriksson et al., 2013; Kirscht et al., 2016). Each monomer has a functional pore formed by six $\alpha$-helical TM domains (TM1-TM6), five connecting loops (LA-LE), and two shorter helices (HB and $\mathrm{HE}$ ). The outward end of $\mathrm{HB}$ and inward end of LE contain a pair of asparagine $(\mathrm{N})$, proline $(\mathrm{P})$, and alamine $(\mathrm{A})$ tandem (NPA) motifs, which constitute the central channel through the membrane (Kirscht et al., 2016). Two NPAs form a conical funnel or traditional hourglass, which are linked at the tip and open outward from LE and inward from TM5 (Törnroth-Horsefield et al., 2010), and are essential for AQP function (Wree et al., 2011; Chen et al., 2018). Within LE, TM2 and TM5, the aromatic/arginine (Ar/R) selective filter (SF) is formed by four residues including aromatic amino acids and an arginine $(\mathrm{R})$ residue; hence its name (de Groot et al., 2003). The SF is located in the outward opening of the channel and allows $\mathrm{H}_{2} \mathrm{O}$ to pass while repelling protons and cations (Eriksson et al., 2013). Multiple physical factors, such as hydrophilic and hydrophobic interactions, electrostatic repulsion, and dipole alignment between amino acid residues within or around the NPA and SF, influence substrate selectivity (Törnroth-Horsefield et al., 2006).

A pivotal step toward the substrate-transporting function of AQPs is the regulation of gating (opening and closing) and trafficking (substrate transport). This has been elucidated for water channels at angstrom ( $⿱$ ) or sub- $\AA$ resolution (Daniels et al., 1999; Fotiadis et al., 2001; Kukulski et al., 2005; Kreida and Törnroth-Horsefield, 2015). Considering spinach Spinacia oleracea SoPIP2;1, channel opening is triggered by the phosphorylation of conserved serine (S) 197 (Johansson et al., 1996; Kukulski et al., 2005), and is expedited by hydrogen bond networks in LD (Törnroth-Horsefield et al., 2010). Channel closure results from the dephosphorylation of S115 in LB and S274 in the C-terminal region of the AQP sequence under conditions of drought stress, or from the protonation of a conserved histidine $(\mathrm{H})$ residue following a decrease in cytoplasmic $\mathrm{pH}$ due to anoxia during flooding. Dissection of SoPIP2;1 crystal structures, both the closed conformation at $2.1 \AA$ and the open conformation at $3.9 \AA$, reveals the importance of LD displacement for gating and trafficking. The dephosphorylation of S115 and S274 prevents outward NPA entry from LB, and inward NPA exit in TM5. In the open conformation of SoPIP2;1, S197 is phosphorylated at LD, LD is displaced up to $16 \AA$, the nitrogen terminus of TM5 extends a further half-turn into the cytoplasm, and NPA entry and exit are promoted. In addition, H193 protonation and interactions between amino acids, including hydrogen bond networks and electrostatic repulsion, also influence the switch between opening and closing of the channel (Törnroth-Horsefield et al., 2010).

Crystal structure analysis of Aqy1, the only AQP in yeast Pichia pastoris, at a sub- $\AA(0.88 \AA)$ resolution, provides evidence for tautomeric reactions to expedite $\mathrm{H}_{2} \mathrm{O}$ transport (Eriksson et al., 2013). Hydrophilic amino acids in NPA and SF interact to bind $\mathrm{H}_{2} \mathrm{O}$ molecules, which are then navigated through the channel. With polar hydrogen bond configurations, four $\mathrm{H}_{2} \mathrm{O}$ molecules per group pass the SF, and then divide into two pairs to pass through the inward NPA region. There are two types of tautomerism between hydrophilic amino acids in the $\mathrm{SF}$. One is proton transfer - the atom $\mathrm{N} \delta$, but not $\mathrm{N} \varepsilon$, of H212 is protonated to provide a proton for L208, with the role of guiding $\mathrm{H}_{2} \mathrm{O}$ movement. The other one is covalent binding - atoms $\mathrm{C} \zeta$ and $\mathrm{N} \eta 2$ of R227 maximally bind to each other, $\mathrm{N} \eta 2$ is closest to the central conduit, and its positive 
charge repels cations, creating favorable conditions for $\mathrm{H}_{2} \mathrm{O}$ to travel through the SF. With this advantage, four compact $\mathrm{H}_{2} \mathrm{O}$ molecules are located within the full space of the SF, where they synchronize to move within and across the SF passage. Due to high impacts of atom tautomerism and hydrogen-bond interactions restricted to the $\mathrm{H}_{2} \mathrm{O}$ molecules in transport, other $\mathrm{H}_{2} \mathrm{O}$ molecules must wait for the next round of the channel opening and trafficking, and proton or cations are unable to enter the SF.

In addition to the structural configuration, biochemical regulation is also indispensable to the function of AQPs. In this aspect, channel gating and trafficking regulation by phosphorylation are ubiquitous for all AQPs (Li and Wang, 2017; Kapilan et al., 2018; Laloux et al., 2018; Nesverova and TörnrothHorsefield, 2019). Additionally critical mechanisms underlying the functional regulation of different AQPs include biotic and abiotic signals. They induce the transport of different substrates (Tian et al., 2016; Ruiz-Lozano and Aroca, 2017; Balestrini et al., 2018; Smirnoff and Arnaud, 2019) by stimulating AQPs themselves with gradients over membranes and by interacting with other proteins (Ji and Dong, 2015a; Roche and TörnrothHorsefield, 2017). These have been topics of many literatures (for example: Maurel and Plassard, 2011; Hara-Chikuma et al., 2015; Ji and Dong, 2015a; Maurel et al., 2015; Yang, 2017; Roche and Törnroth-Horsefield, 2017) and will not been discussed in this article.

\section{CONTROL OF SUBSTRATE SPECIFICITIES}

This is a question for AQPs capable of transporting substrates other than $\mathrm{H}_{2} \mathrm{O}$, especially those that have multiple permeation properties. In addition to $\mathrm{H}_{2} \mathrm{O}$, approximately 20 other substrates require $A Q P s$ to move between the exterior and interior of cells, and between organelles (Laloux et al., 2018). A fifth pore created by four AQP monomers of a homotetramer in the lipid bilayer (Wang et al., 2007) or yeast membrane (Otto et al., 2010) has been proposed for gas $\left(\mathrm{CO}_{2}\right.$ and $\left.\mathrm{O}_{2}\right)$ and ion transport (Kaldenhoff et al., 2014). Moreover, many AQPs have more than one substrate (Kreida and Törnroth-Horsefield, 2015; Maurel et al., 2015; Fox et al., 2017; Laloux et al., 2018). Examples include AtPIP2;1 for $\mathrm{H}_{2} \mathrm{O} / \mathrm{H}_{2} \mathrm{O}_{2}$ (Dynowski et al., 2008; Verdoucq et al., 2008), AtPIP1;4 for $\mathrm{H}_{2} \mathrm{O} / \mathrm{H}_{2} \mathrm{O}_{2} / \mathrm{CO}_{2}$ ( $\mathrm{Li}$ et al., 2015; Tian et al., 2016), and TIPs for $\mathrm{H}_{2} \mathrm{O}, \mathrm{H}_{2} \mathrm{O}_{2}$ and/or ammonia $\left(\mathrm{NH}_{3}\right.$; Maurel et al., 1993; Loque et al., 2005; Bárzana et al., 2014) transport. Regulation of gating and trafficking must differ considerably between specialist channels, different generalist channels, and channels for $\mathrm{H}_{2} \mathrm{O}$ and a different substrate. Variation in NPA diameter, the composition and width of SF, neighboring residues, and their interactions with each other and with the substrate might explain multiple functions of AQPs/PIPs in the transport of different substrates, and the multiple substrate transport capacities of a single AQP/PIP (Fox et al., 2017).

Recently, a smart solution was proposed in a study on the $1.18 \AA$ crystal structure of AtTIP2;1 (Kirscht et al., 2016). That study characterized AtTIP2;1 as an $\mathrm{NH}_{3}$ transport channel, which functions with an extended SF. The channel diameter in the NPA region is smaller than that of other AQPs, but remains constant at $\sim 3 \AA$ along the channel; this is in contrast to the narrowing of SF in other AQPs. The topological positions of four SF residues in TM2, TM5, LE, and HE are thought to determine substrate selectivity (de Groot et al., 2001). Consistent with this model, TIP2s deviate from other AQPs in terms of the wider SF, which is mainly caused by an isoleucine (I185) in TM5, replacing a histidine that is conserved in water-specific AQPs (Kirscht et al., 2016). The most striking feature of the SF in AtTIP2; 1 is the R200 located in $\mathrm{HE}$, while the arginine in $\mathrm{HE}$ is conserved in most AQPs. In AtTIP2;1, the R200 side chain is located at the edge of the channel due to the H131 situated in LC, making histidine the fifth residue of the extended SF. The position of this arginine is further stabilized by a hydrogen bond with histidine (H63) in TM2, which occupies the same space as the corresponding aromatic residues of water and glycerol channels without direct effects on the channel opening (Kirscht et al., 2016). Moreover, $\mathrm{H} 131$ in LC interacts directly with the substrate in the selectivity region. These structural features define the extended SF at five positions: I185, R200, H131, and H63, which have properties and configurations that establish the novel SF, plus G191 in LE, which is conserved in the canonical and extended SF. The concept of extended SF is instructive to conceiving study schemes before initiating analysis of APQ/PIP channels for transport of $\mathrm{H}_{2} \mathrm{O}_{2}$ and more substrates other than $\mathrm{H}_{2} \mathrm{O}$ and $\mathrm{NH}_{3}$.

\section{STRUCTURAL BASIS OF PIPS FOR MEDIATION OF $\mathrm{H}_{2} \mathrm{O}_{2}$ TRANSPORT}

Until the structural basis of PIP/AQP functions in $\mathrm{H}_{2} \mathrm{O}_{2}$ transport is dissected, no more than inspiration can be deduced from referencing the crystal structures of SoPIP2;1 for $\mathrm{NH}_{3}$ transport (Kirscht et al., 2016) and both Aqy1 (Eriksson et al., 2013) and AtTIP2;1 (Törnroth-Horsefield et al., 2010) for $\mathrm{H}_{2} \mathrm{O}$ transport. The topological displacement of the connecting loop (Törnroth-Horsefield et al., 2010) may have a broad importance for AQPs. Tautomeric reactions (Eriksson et al., 2013) and the SF extension (Kirscht et al., 2016) might be used by certain PIPs/AQPs to expedite $\mathrm{H}_{2} \mathrm{O}_{2}$ transport. However, these features are likely to be insufficient to support $\mathrm{H}_{2} \mathrm{O}_{2}$ transport, due to the difference in diameter/molecular mass of $\mathrm{H}_{2} \mathrm{O}_{2}(3.70 \AA / 34)$, $\mathrm{H}_{2} \mathrm{O}(2.96 \AA / 33)$ and $\mathrm{NH}_{3}(<2.96 \AA / 17)$, and in the Ar/R SF features. The location and composition of the SF is identical (F87, $\mathrm{H} 126, \mathrm{~T} 225, \mathrm{R} 231$ ) in the $\mathrm{H}_{2} \mathrm{O}_{2}$ channel AtPIP2;1 (Rodrigues et al., 2017) and the water channel SoPIP2;1 (Kirscht et al., 2016). However, the SF composition shared by AtPIP2;1 and SoPIP2;1 is distinct from that in the corresponding positions (G87, I126, L225, and T231) of the $\mathrm{H}_{2} \mathrm{O}_{2}$ channel AtPIP1;4 (Tian et al., 2016). AtPIP1;4 is the same length as OsPIP2;1, but possesses six more residues than SoPIP2;1, with a predicted Ar/R SF comprising F95, H224, T231, and R239 (Figure 3B). If the SF extension permits AQPs to mediate $\mathrm{H}_{2} \mathrm{O}_{2}$ transport, the degree of the SF extension must be considerably higher than that in the $\mathrm{NH}_{3}$ transport channel (Kirscht et al., 2016). 
Three issues are considered to infer the structural basis of the function of PIPs in $\mathrm{H}_{2} \mathrm{O}_{2}$ transport between the outside and inside of plant cells. First, the apocytoplastic transport of $\mathrm{H}_{2} \mathrm{O}_{2}$ is more intricate as compared to the signal shift ways by the cell-to-cell traveling via plasmodesmata (Wang et al., 2009) and via vesicle-aided trafficking between organelles through the ER system within the cell interior (Ashtamker et al., 2007; Melo et al., 2017). Second, $\mathrm{H}_{2} \mathrm{O}_{2}$ transport in and out of plant cells is not constant throughout the life circle of plants (Dynowski et al., 2008; Tian et al., 2016). Third, $\mathrm{H}_{2} \mathrm{O}_{2}$ trafficking across the PM is induced but is not constitutive, and occurs only when apoplastic $\mathrm{H}_{2} \mathrm{O}_{2}$ is generated in response to pathogens, microbial patterns, or environmental signals (Levine et al., 1994; Xin et al., 2015; Liu and He, 2016; Tian et al., 2016).

Plasma membrane sensing of these distinct signals will promote $\mathrm{H}_{2} \mathrm{O}_{2}$ generation in apoplasts and its immediate translocation into the cytoplasm (Ausubel, 2005; Ashtamker et al., 2007; Tian et al., 2016) by three possible mechanisms. One is inductivity (Figure $\mathbf{3 A}$ ). When plants are infected by a pathogen or respond to a microbial pattern, such as Hpal or flg22, the enzymatic activity of NOX is induced to catalyze the generation of $\mathrm{H}_{2} \mathrm{O}_{2}$ by peroxidation and superoxidation in PMs (Tian et al., 2016; Smirnoff and Arnaud, 2019). The generated $\mathrm{H}_{2} \mathrm{O}_{2}$ accumulates, and the concentration increases temporarily in the apoplast. This creates a gradient from the outside to the inside of the cell (Tian et al., 2016), and induces the PIP channel to function (Tian et al., 2016).

The second mechanism is speculated to be the combination of factors (Figure 3C) found in SoPIP2;1 (Törnroth-Horsefield et al., 2010), Aqy1 (Eriksson et al., 2013), and AtTIP2;1 (Kirscht et al., 2016). Combined factors facilitate the passage of $\mathrm{H}_{2} \mathrm{O}_{2}$ through the PIP channel, which could be established by SF extension (Kirscht et al., 2016), and optimized by amino acid protonation (Eriksson et al., 2013). $\mathrm{H}_{2} \mathrm{O}_{2}$ generation $\left(2 \mathrm{O}_{2}{ }^{-}+\right.$ $2 \mathrm{H}^{+}=\mathrm{H}_{2} \mathrm{O}_{2}$ ) requires protons, and may reduce the likelihood that amino acid residues near the SF and NPA regions are protonated. As the protonation navigates $\mathrm{H}_{2} \mathrm{O}$ movement along the channel (Eriksson et al., 2013), decreased protonation will disturb $\mathrm{H}_{2} \mathrm{O}$ transport. This might promotes the transport of $\mathrm{H}_{2} \mathrm{O}_{2}$ over $\mathrm{H}_{2} \mathrm{O}$ through a PIP channel once a sufficient diameter is reached (>3.70 $\AA$ ).

The third mechanism is supposed to be biochemical responses (Figure 3C) associated with the regulation of PM remodeling injury and repair (Laliberté and Sanfaçon, 2010; Santi-Rocca and Blanchard, 2017). PM remodeling is triggered by the binding of an active extrinsic protein, including microbial patterns such as Hpal (Li et al., 2015; Tian et al., 2016), bacterial T3 translocators such as HrpF (Büttner et al., 2002; Li et al., 2011), and bacterial effectors (Hubber and Roy, 2010; Domingues et al., 2016; Dong et al., 2016). Binding of these bioactive proteins affects the PM integrity (Ji and Dong, 2015a; Guignot and Tran Van Nhieu, 2016). Reduced PM integrity is advantageous for solute influx, which, however, is strictly regulated by proteins and lipids that recognize microbial patterns, T3 effectors, or translocators (Gilbert et al., 2014).

The former two mechanisms may synergize in the gating and trafficking regulation, requiring AtPIP1;4 to transport $\mathrm{H}_{2} \mathrm{O}_{2}$ in plants grown under regular conditions without any input signal, except for externally applied $\mathrm{H}_{2} \mathrm{O}_{2}$ or $\mathrm{H}_{2} \mathrm{O}_{2}$ induced by a pathogen or a microbial pattern (Tian et al., 2016). The third mechanism may occur in the presence of Hpal following application to plants or production in transgenic plants, in which AtPIP1;4 interacts with Hpal (Li et al., 2015) to increase the substrate transport function. Studies should aim to verify this hypothesis in order to elucidate the structures of PIP orthologs as transport channels for $\mathrm{H}_{2} \mathrm{O}_{2}$ or different substrates.

\section{CONCLUSION AND PERSPECTIVES}

Finite research performed on these case studies is based on a solid foundation obtained through extensive studies; research on the structural regulation of PIP function in plant infection and immunity is invited. The first case study on Hpa1-mediated, OsPIP1;3-associated, and virulence-relevant PthXo1 translocation offers multiple experimental avenues to characterize interactions between T3 translocators and their receptors at target PMs, as well as the associated implications for effector translocation and virulence. The two subjects discussed here are yet to be thoroughly studied. First, which of the assumed delivery lanes is used by different effectors is a long-standing question for all plant-pathogenic bacteria. Xoo possesses more than 30 effectors secreted by the T3 system (White et al., 2009), similar to the number in other bacteria. Further study is needed to identify all T3 effectors in the three proposed mechanisms: translocon-independent pore formation (Figure 1), endocytosis with PM protein or lipid trafficking (Figures 1, 2), and translocon-dependent delivery (Figure 1). The second subject includes the contribution of PM lipids and proteins to T3 effector translocation. T3 translocon assembly or pore formation must recruit both lipids and proteins situated in plant PMs (Büttner et al., 2008; Gilbert et al., 2014; Heilmann and Heilmann, 2015; Ji and Dong, 2015b; Guignot and Tran Van Nhieu, 2016). It would be of great interest to determine how effectors are internalized with PM protein or lipid trafficking, and how protein and lipid receptors of T3 translocators coordinate their actions to generate pores or translocons in plant PMs.

The second case study discusses AtPIP1;4-regulated, Hpa1promoted, and immunity-linked $\mathrm{H}_{2} \mathrm{O}_{2}$ transport, and establishes a cytological connection between the generation and function of $\mathrm{H}_{2} \mathrm{O}_{2}$ in the apoplast and cytoplasm, respectively (Tian et al., 2016). The cytoplasmic import of $\mathrm{H}_{2} \mathrm{O}_{2}$ bridges a physical gap, which was unknown for at least 20 years since the biphasic $\mathrm{H}_{2} \mathrm{O}_{2}$ accumulation following induction was awarded biological significance (Levine et al., 1994). AtPIP1;4mediated $\mathrm{H}_{2} \mathrm{O}_{2}$ translocation is a pivotal step in apocytoplastic signal transduction for intracellular immunity pathways, which regulate SAR and PTI responses, leading to plant resistance against diseases (Dong et al., 1999; Chen et al., 2008a,b; Choi et al., 2013; Zhao et al., 2014). The future focus of studies will be difficult, highlighting the regulation of gating and trafficking of the AtPIP1;4 channel for $\mathrm{H}_{2} \mathrm{O}_{2}$ transport. To date, the structures of AQP channels have only been determined for the transport of $\mathrm{NH}_{3}$ (Kirscht et al., 2016) 
and $\mathrm{H}_{2} \mathrm{O}$ (Daniels et al., 1999; Fotiadis et al., 2001; Kukulski et al., 2005; Kreida and Törnroth-Horsefield, 2015), and almost 20 substrates remain to be understood (Laloux et al., 2018). Rational hypotheses on structural themes in both gating and trafficking (Kreida and Törnroth-Horsefield, 2015) requires the efforts of researchers to explore structural mechanisms that govern diverse AQP channels. It is necessary to dissect the conformation of AtPIP1;4 (Figures 3B,C) involved in $\mathrm{H}_{2} \mathrm{O}_{2}$ transport in response pathogens or patterns (Figure $\mathbf{3 A}$ ). It is especially necessary to study whether the $\mathrm{H}_{2} \mathrm{O}_{2}$ transport is facilitated by combined impetuses, including the SF extension, amino acid residue interactions (Figure 3C), and PM protein trafficking (Figure 2).

The two case studies have been designed to converge at the intersection Hpal-PIP cooperation and branch into two directions. One targets plant immunity, for which Hpal functions as a bacterial pattern in a pathogen-independent manner. The other contributes to plant infection, in which Hpal acts as a T3 translocator after secretion by the bacteria, and mediates the translocation of virulent effectors that lead to disease. These findings provide insight into disease control either through induced immunity, or the prevention of bacteria from usurping the substrate transport gate. Practical application of both strategies to strengthen crop protection (Krinke et al., 2007; Chen et al., 2008b; Fu et al., 2014; Wang D. et al., 2014; Li et al., 2019)

\section{REFERENCES}

Abascal, F., Irisarri, I., and Zardoya, R. (2014). Diversity and evolution of membrane intrinsic proteins. Biochim. Biophys. Acta 1840, 1468-1481. doi: 10.1016/j.bbagen.2013.12.001

Adam, P. R., Barta, M. L., and Dickenson, N. E. (2017). "Characterization of type three secretion system translocator interactions with phospholipid membranes," in Type 3 Secretion Systems: Methods and Protocols, Methods in Molecular Biology, Vol. 1531, eds M. L. Nilles and D. L. J. Condry (New York, NY: Springer Science + Business Media), 81-91. doi: 10.1007/978-1-49396649-3_7

Aguayo, D., Pacheco, N., Morales, E. H., Collao, B., Luraschi, R., Cabezas, C., et al. (2015). Hydrogen peroxide and hypochlorous acid influx through the major S. typhimurium porin OmpD is affected by substitution of key residues of the channel. Arch. Biochem. Biophys. 568, 38-45. doi: 10.1016/j.abb.2015. 01.005

Allgood, S. C., and Neunuebel, M. R. (2018). The recycling endosome and bacterial pathogens. Cell. Microbiol. 20:e12857. doi: 10.3389/fimmu.2016.00084

Alvarez, M. E., Pennell, R. L., Meijer, R.-J., Ishikawa, A., Dixon, R. A., and Lamb, C. (1998). Reactive oxygen intermediates mediate a systemic signal network in the establishment of plant immunity. Cell 92, 773-784. doi: 10.1016/s00928674(00)81405- 1

Asai, T., Tena, G., Plotnikova, J., Willmann, M. R., Chiu, W. L., Gomez-Gomez, L., et al. (2002). MAP kinase signalling cascade in Arabidopsis innate immunity. Nature 415, 977-983. doi: 10.1038/415977a

Ashtamker, C., Kiss, V., Sagi, M., Davydov, O., and Fluhr, R. (2007). Diverse subcellular locations of cryptogein-induced reactive oxygen species production in tobacco Bright Yellow-2 cells. Plant Physiol. 143, 1817-1826. doi: 10.1104/ pp.106.090902

Ausubel, F. M. (2005). Are innate immune signaling pathways in plants and animals conserved? Nat. Immunol. 6, 973-979. doi: 10.1038/ni1253

Balestrini, R., Chitarra, W., Antoniou, C., Ruocco, M., and Fotopoulos, V. (2018). Improvement of plant performance under water deficit with the employment of biological and chemical priming agents. J. Agric. Sci. 156, 680-688. doi: $10.1017 /$ s0021859618000126 will integrate with crop involvement by using AQPs from plants themselves (Ruiz-Lozano and Aroca, 2017; Balestrini et al., 2018) and from symbiotic microbes as well (Kikuchi et al., 2016; Desaki et al., 2018).

\section{AUTHOR CONTRIBUTIONS}

LZ, LC, and HD drafted the manuscript. LZ predicted the 3D structure of AtPIP1;4. HD finalized the manuscript.

\section{FUNDING}

This study was supported by Natural Science Foundation of China (Grant No. 31772247) and China National Key Research and Development Plan (Grant No. 2017YFD0200901) to HD and Talent Recruitment Funding of Shandong Agricultural University (Grant No. 20171226) to HD, LC, and LZ.

\section{ACKNOWLEDGMENTS}

We thank Mr. Hao Wang (doctoral student in the laboratory) for his advice in the structural analysis.

Bao, Y. (2017). Advances in Experimental Medicine and Biology 969 Aquaporins. Dordrecht: Springer Science + Business Media B.V, 279.

Bárzana, G., Aroca, R., Bienert, G. P., Chaumont, F., and Ruiz-Lozano, J. M. (2014). New insights into the regulation of aquaporins by the arbuscular mycorrhizal symbiosis in maize plants under drought stress and possible implications for plant performance. Mol. Plant Microbe Interact. 27, 349-363. doi: 10.1094/ MPMI-09-13-0268-R

Bárzana, G., Aroca, R., and Ruiz-Lozano, J. M. (2015). Localized and non-localized effects of arbuscular mycorrhizal symbiosis on accumulation of osmolytes and aquaporins and on antioxidant systems in maize plants subjected to total or partial root drying. Plant Cell Environ. 38, 1613-1627. doi: 10.1111/pce. 12507

Benabdillah, R., Mota, L. J., Lützelschwab, S., Demoinet, E., and Cornelis, G. R. (2004). Identification of a nuclear targeting signal in YopM from Yersinia spp. Microb. Pathog. 36, 247-261. doi: 10.1016/j.micpath.2003.12.006

Bethke, G., Pecher, P., Eschen-Lippold, L., Tsuda, K., Katagiri, F., Glazebrook, J., et al. (2012). Activation of the Arabidopsis thaliana mitogen-activated protein kinase MPK11 by the flagellin-derived elicitor peptide, flg22. Mol. Plant Microbe Interact. 25, 471-480. doi: 10.1094/MPMI-11-11-0281

Bian, H., Zhang, L., Chen, L., Wang, W., Ji, H., and Dan, S. (2019). Real-time monitoring of translocation of selected type III effectors from Xanthomonas oryzae pv. oryzae into rice cells. J. Biosci. (in press).

Bienert, G. P., and Chaumont, F. (2014). Aquaporin-facilitated transmembrane diffusion of hydrogen peroxide. Biochim. Biophys. Acta 1840, 1596-1604. doi: 10.1016/j.bbagen.2013.09.017

Bienert, G. P., Moller, A. L., Kristiansen, K. A., Schulz, A., Moller, I. M., Schjoerring, J. K., et al. (2007). Specific aquaporins facilitate the diffusion of hydrogen peroxide across membranes. J. Biol. Chem. 282, 1183-1192. doi: 10.1074/jbc. M603761200

Bienert, G. P., Schjoerring, J. K., and Jahn, T. P. (2006). Membrane transport of hydrogen peroxide. Biochim. Biophys. Acta 1758, 994-1003. doi: 10.1016/j. bbamem.2006.02.015

Bigeard, J., Colcombet, J., and Hirt, H. (2015). Signaling mechanisms in patterntriggered immunity (PTI). Mol. Plant 8, 521-539. doi: 10.1016/j.molp.2014. 12.022 
Bocsanczy, A. M., Nissinen, R. M., Oh, C. S., and Beer, S. V. (2008). HrpN of Erwinia amylovora functions in the translocation of DspA/E into plant cells. Mol. Plant Pathol. 9, 425-434. doi: 10.1111/j.1364-3703.2008.00471.x

Brown, D. (2017). The discovery of water channels (aquaporins). Ann. Nutr. Metab. 70(Suppl. 1), 37-42. doi: 10.1159/000463061

Büttner, C. R., Sorg, I., Cornelis, G. R., Heinz, D. W., and Niemann, H. H. (2008). Structure of the Yersinia enterocolitica type III secretion translocator chaperone SycD. J. Mol. Biol. 375, 997-1012. doi: 10.1016/j.jmb.2007.11.009

Büttner, D. (2012). Protein export according to schedule: architecture, assembly, and regulation of type III secretion systems from plant- and animal-pathogenic bacteria. Microbiol. Mol. Biol. Rev. 76, 262-310. doi: 10.1128/MMBR.05017-11

Büttner, D. (2016). Behind the lines-actions of bacterial type III effector proteins in plant cells. FEMS Microbiol. Rev. 40, 894-937. doi: 10.1093/femsre/ fuw026

Büttner, D., and Bonas, U. (2002). Port of entry - the type III secretion translocon. Trends Microbiol. 10, 186-192. doi: 10.1016/s0966-842x(02)02331-4

Büttner, D., Nennstiel, D., Klüsener, B., and Bonas, U. (2002). Functional analysis of HrpF, a putative type III translocon protein from Xanthomonas campestris pv. vesicatoria. J. Bacteriol. 184, 2389-2398. doi: 10.1128/jb.184.9.2389-2398. 2002

Calvo-Polanco, M., Sánchez-Castro, I., Cantos, M., García, J. L., Azcón, R., RuizLozano, J. M., et al. (2016). Effects of different arbuscular mycorrhizal fungal backgrounds and soils on olive plants growth and water relation properties under well-watered and drought conditions. Plant Cell Environ. 39, 2498-2514. doi: $10.1111 /$ pce. 12807

Cao, H., Glazebrook, J., Clarke, J. D., Volko, S., and Dong, X. (1997). The Arabidopsis NPR1 gene that controls systemic acquired resistance encodes a novel protein containing ankyrin repeats. Cell 88, 57-63. doi: 10.1016/s00928674(00)81858-9

Centrone, M., Ranieri, M., Di Mise, A., Berlingerio, S. P., Russo, A., Deen, P. M. T., et al. (2017). AQP2 abundance is regulated by the E3-ligase CHIP via HSP70. Cell. Physiol. Biochem. 44, 515-531. doi: 10.1159/000485088

Chakravarthy, S., Huot, B., and Kvitko, B. H. (2017). Effector translocation: Cya reporter assay. Methods Mol. Biol. 1615, 473-487. doi: 10.1007/978-1-49397033-9_33

Chatterjee, S., Chaudhury, S., McShan, A. C., Kaur, K., and De Guzman, R. N. (2013). Structure and biophysics of type III secretion in bacteria. Biochemistry 52, 2508-2517. doi: 10.1021/bi400160a

Chaumont, F., Barrieu, F., Wojcik, E., Chrispeels, M. J., and Jung, R. (2001). Aquaporins constitute a large and highly divergent protein family in maize. Plant Physiol. 125, 1206-1215. doi: 10.1104/pp.125.3.1206

Chen, G., Wang, W., Chen, H., Dai, W., Peng, X., Li, X., et al. (2018). In vitro expression and functional characterization of NPA motifs in aquaporins of Nosema bombycis. Parasitol. Res. 117, 3473-3479. doi: 10.1007/s00436-0186044-y

Chen, L., Qian, J., Long, J., Yin, Q., Zhang, C., Wu, X., et al. (2008a). Identification of specific fragments of $\mathrm{HpaG}_{X o o c}$, a harpin protein from Xanthomonas oryzae pv. oryzicola, that induces disease resistance and enhanced growth in rice. Phtopathology 98, 781-791. doi: 10.1094/PHYTO-98-7-0781

Chen, L., Zhang, S. J., Zhang, S. S., Qu, S., Long, J., Ren, H., et al. (2008b). A fragment of the Xanthomonas oryzae pv. oryzicola harpin $\mathrm{HpaG}_{\text {Xooc }}$ reduces disease and increases yield of rice in extensive grower plantings. Phytopathology 98, 792-802. doi: 10.1094/PHYTO-98-7-0792

Choi, M. S., Kim, W., Lee, C., and Oh, C. S. (2013). Harpins, multifunctional proteins secreted by Gram-negative plant-pathogenic bacteria. Mol. Plant Microbe Interact. 26, 1115-1122. doi: 10.1094/MPMI-02-13-0050-CR

Cybulsky, A. V. (2017). Endoplasmic reticulum stress, the unfolded protein response and autophagy in kidney diseases. Nat. Rev. Nephrol. 13, 681-696. doi: $10.1038 /$ nrneph.2017.129

Daniels, M. J., Chrispeels, M. J., and Yeager, M. (1999). Projection structure of a plant vacuole membrane aquaporin by electron cryo-crystallography. J. Mol. Biol. 294, 1337-1349. doi: 10.1006/jmbi.1999.3293

Daudi, A., Cheng, Z., O’Brien, J. A., Mammarella, N., Khan, S., Ausubel, F. M., et al. (2012). The apoplastic oxidative burst peroxidase in Arabidopsis is a major component of pattern-triggered immunity. Plant Cell 24, 275-287. doi: 10.1105/tpc.111.093039

de Groot, B. L., Engel, A., and Grubmüller, H. (2001). A refined structure of human aquaporin-1. FEBS Lett. 504, 201-211. doi: 10.1016/S0014-5793(01)02743-0 de Groot, B. L., Frigato, T., Helms, V., and Grubmuller, H. (2003). The mechanism of proton exclusion in the aquaporin-1 water channel. J. Mol. Biol. 333, 279-293. doi: 10.1016/j.jmb.2003.08.003

de Groot, B. L., and Grubmuller, H. (2001). Water permeation across biological membranes: mechanism and dynamics of aquaporin-1 and GlpF. Science 294, 2353-2357. doi: 10.1126/science.1062459

Desaki, Y., Miyata, K., Suzuki, M., Shibuya, N., and Kaku, H. (2018). Plant immunity and symbiosis signaling mediated by LysM receptors. Innate Immun. 24, 92-100. doi: 10.1177/1753425917738885

Dik, D. A., Marous, D. R., Fisher, J. F., and Mobashery, S. (2017). Lytic transglycosylases: concinnity in concision of the bacterial cell wall. Crit. Rev. Biochem. Mol. Biol. 52, 503-542. doi: 10.1080/10409238.2017.1337705

Domingues, L., Ismail, A., Charro, N., Rodríguez-Escudero, I., Holden, D. W., Molina, M., et al. (2016). The Salmonella effector SteA binds phosphatidylinositol 4-phosphate for subcellular targeting within host cells. Cell. Microbiol. 18, 949-969. doi: 10.1111/cmi.12558

Dong, H., Delaney, T. P., Bauer, D. W., and Beer, S. V. (1999). Harpin induces disease resistance in Arabidopsis through the systemic acquired resistance pathway mediated by salicylic acid and the NIM1 gene. Plant J. 20, 207-215. doi: 10.1046/j.1365-313x.1999.00595.x

Dong, N., Niu, M., Hu, L., Yao, Q. I., Zou, R., and Shao, F. (2016). Modulation of membrane phosphoinositide dynamics by the phosphatidylinositide 4-kinase activity of the Legionella LepB effector. Nat. Microbiol. 2:16236. doi: 10.1038/ nmicrobiol.2016.236

Dynowski, M., Schaaf, G., Loque, D., Moran, O., and Ludewig, U. (2008). Plant plasma membrane water channels conduct the signalling molecule $\mathrm{H}_{2} \mathrm{O}_{2}$. Biochem. J. 414, 53-61. doi: 10.1042/BJ20080287

Eriksson, U. K., Fischer, G., Friemann, R., Enkavi, G., Tajkhorshid, E., and Neutze, R. (2013). Subangstrom resolution X-ray structure details aquaporin-water interactions. Science 340, 1346-1349. doi: 10.1126/science.1234306

Finsel, I., and Hilbi, H. (2015). Formation of a pathogen vacuole according to Legionella pneumophila: how to kill one bird with many stones. Cell. Microbiol. 17, 935-950. doi: 10.1111/cmi.12450

Fotiadis, D., Jeno, P., Mini, T., Wirtz, S., Muller, S. A., Fraysse, L., et al. (2001). Structural characterization of two aquaporins isolated from native spinach leaf plasma membranes. J. Biol. Chem. 276, 1707-1714. doi: 10.1074/jbc. M009383200

Fox, A. R., Maistriaux, L. C., and Chaumont, F. (2017). Toward understanding of the high number of plant aquaporin isoforms and multiple regulation mechanisms. Plant Sci. 264, 179-187. doi: 10.1016/j.plantsci.2017.07.021

Fu, D., Libson, A., Miercke, L. J., Weitzman, C., Nollert, P., Krucinski, J., et al. (2000). Structure of a glycerol-conducting channel and the basis for its selectivity. Science 290, 481-486. doi: 10.1126/science.290.5491.481

Fu, M., Xu, M., Zhou, T., Wang, D., Tian, S., Zhang, C., et al. (2014). Transgenic expression of a functional fragment of harpin protein Hpal in wheat induces the phloem-based defence against English grain aphid. J. Exp. Bot. 65, 1439-1453. doi: 10.1093/jxb/ert488

Galletti, R., Ferrari, S., and De Lorenzo, G. (2011). Arabidopsis MPK3 and MPK6 play different roles in basal and oligogalacturonide- or flagellin-induced resistance against Botrytis cinerea. Plant Physiol. 157, 804-814. doi: 10.1104/pp. 111.174003

Gaytán, M. O., Monjarás Feria, J., Soto, E., Espinosa, N., Benítez, M., and Georgellis, D. (2018). Novel insights into the mechanism of SepLmediated control of effector secretion in enteropathogenic Escherichia coli. Microbiologyopen 7:e00571. doi: 10.1002/mbo3.571

Gilbert, R. J., Dalla Serra, M., Froelich, C. J., Wallace, M. I., and Anderluh, G. (2014). Membrane pore formation at protein-lipid interfaces. Trends Biochem. Sci. 39, 510-516. doi: 10.1016/j.tibs.2014.09.002

Gomes, D., Agasse, A., Thiébaud, P., Delrot, S., Gerós, H., and Chaumont, F. (2009). Aquaporins are multifunctional water and solute transporters highly divergent in living organisms. Biochim. Biophys. Acta 1788, 1213-1228. doi: 10.1016/j.bbamem.2009.03.009

Goure, J., Pastor, A., Faudry, E., Chabert, J., Dessen, A., and Attree, I. (2004). The V antigen of Pseudomonas aeruginosa is required for assembly of the functional PopB/PopD translocation pore in host cell membranes. Infect. Immun. 72, 4741-4750. doi: 10.1128/IAI.72.8.4741-4750.2004

Gudesblat, G. E., Iusem, N. D., and Morris, P. C. (2007). Guard cell-specific inhibition of Arabidopsis MPK3 expression causes abnormal stomatal responses 
to abscisic acid and hydrogen peroxide. New Phytol. 173, 713-721. doi: 10.1111/ j.1469-8137.2006.01953.x

Guignot, J., and Tran Van Nhieu, G. (2016). Bacterial control of pores induced by the type III secretion system: mind the gap. Front. Immunol. 7:84. doi: 10.3389/fimmu.2016.00084

Guo, M., Tian, F., Wamboldt, Y., and Alfano, J. R. (2009). The majority of the type III effector inventory of Pseudomonas syringae pv. tomato DC3000 can suppress plant immunity. Mol. Plant Microbe Interact. 22, 1069-1080. doi: 10.1094/MPMI-22-9-1069

Haapalainen, M., Engelhardt, S., Küfner, I., Li, C. M., Nürnberger, T., Lee, J., et al. (2011). Functional mapping of harpin HrpZ of Pseudomonas syringae reveals the sites responsible for protein oligomerization, lipid interactions and plant defence induction. Mol. Plant Pathol. 12, 151-166. doi: 10.1111/j.1364-3703. 2010.00655.x

Hammond, G. R., Fischer, M. J., Anderson, K. E., Holdich, J., Koteci, A., Balla, T., et al. (2009). PI4P and $\mathrm{PI}(4,5) \mathrm{P}_{2}$ are essential but independent lipid determinants of membrane integrity. Science 37, 727-730. doi: 10.1126/science. 1222483

Hara-Chikuma, M., Satooka, H., Watanabe, S., Honda, T., Miyachi, Y., Watanabe, T., et al. (2015). Aquaporin-3-mediated hydrogen peroxide transport is required for NF-кB signalling in keratinocytes and development of psoriasis. Nat. Commun. 23:7454. doi: 10.1038/ncomms8454

Hausner, J., Hartmann, N., Jordan, M., and Büttner, D. (2017). The predicted lytic transglycosylase $\mathrm{HpaH}$ from Xanthomonas campestris pv. vesicatoria associates with the type III secretion system and promotes effector protein translocation. Infect. Immun. 85:e0788-16. doi: 10.1128/IAI.00788-16

He, J., and Yang, B. (2019). Aquaporins in renal diseases. Intl. J. Mol. Sci. 20:366. doi: 10.3390/ijms20020366

Heckwolf, M., Pater, D., Hanson, D. T., and Kaldenhoff, R. (2011). The Arabidopsis thaliana aquaporin AtPIP1;2 is a physiologically relevant $\mathrm{CO}_{2}$ transport facilitator. Plant J. 67, 795-804. doi: 10.1111/j.1365-313X.2011.04634.x

Heilmann, M., and Heilmann, I. (2015). Plant phosphoinositides-complex networks controlling growth and adaptation. Biochim. Biophys. Acta 851, 759-769. doi: 10.1016/j.bbalip.2014.09.018

Hirano, K., Zuber, C., Roth, J., and Ziak, M. (2003). The proteasome is involved in the degradation of different aquaporin-2 mutants causing nephrogenic diabetes insipidus. Am. J. Pathol. 163, 111-120. doi: 10.1016/S0002-9440(10)63635-8

Hooijmaijers, C., Rhee, J. Y., Kwak, K. J., Chung, G. C., Horie, T., and Katsuhara, M. (2012). Hydrogen peroxide permeability of plasma membrane aquaporins of Arabidopsis thaliana. J. Plant Res. 125, 147-153. doi: 10.1007/s10265-0110413-2

Horsefield, R., Norden, K., Fellert, M., Backmark, A., Törnroth-Horsefield, S., van Scheltinga, A. C., et al. (2008). High-resolution x-ray structure of human aquaporin 5. Proc. Natl. Acad. Sci. U.S.A. 105, 13327-13332. doi: 10.1073/pnas. 0801466105

Huang, B., Wang, H., and Yang, B. (2017). "Water transport mediated by other membrane proteins," in Advances in Experimental Medicine and Biology 969 Aquaporins, ed. B. Yang (Dordrecht: Springer Science + Business Media B.V), 251-261. doi: 10.1007/978-94-024-1057-0_17

Hubber, A., and Roy, C. R. (2010). Modulation of host cell function by Legionella pneumophila type IV effectors. Annu. Rev. Cell Dev. Biol. 26, 261-283. doi: 10.1146/annurev-cellbio-100109-104034

Ji, H., and Dong, H. (2015a). Biological significance and topological basis of aquaporin-partnering protein-protein interactions. Plant Signal. Behav. 10:e1011947. doi: 10.1080/15592324.2015.1011947

Ji, H., and Dong, H. (2015b). Key steps in type III secretion system (T3SS) towards translocon assembly with potential sensor at plant plasma membrane. Mol. Plant Pathol. 16, 762-773. doi: 10.1111/mpp.12223

Johansson, I., Larsson, C., Ek, B., and Kjellbom, P. (1996). The major integral proteins of spinach leaf plasma membranes are putative aquaporins and are phosphorylated in response to $\mathrm{Ca}^{2+}$ and apoplastic water potential. Plant Cell 8, 1181-1191. doi: 10.1105/tpc.8.7.1181

Kaku, H., Nishizawa, Y., Ishii-Minami, N., Akimoto-Tomiyama, C., Dohmae, N., Takio, K., et al. (2006). Plant cells recognize chitin fragments for defense signaling through a plasma membrane receptor. Proc. Natl. Acad. Sci. U.S.A. 103, 11086-11091. doi: 10.1073/pnas.0508882103
Kaldenhoff, R., Kai, L., and Uehlein, N. (2014). Aquaporins and membrane diffusion of $\mathrm{CO}_{2}$ in living organisms. Biochim. Biophys. Acta 1840, 1592-1595. doi: 10.1016/j.bbagen.2013.09.037

Kamsteeg, E. J., Hendriks, G., Boone, M., Konings, I. B., Oorschot, V., van der Sluijs, P., et al. (2006). Short-chain ubiquitination mediates the regulated endocytosis of the aquaporin-2 water channel. Proc. Natl. Acad. Sci. U.S.A. 103, 18344-18349. doi: 10.1073/pnas.0604073103

Kapilan, R., Vaziri, M., and Zwiazek, J. J. (2018). Regulation of aquaporins in plants under stress. Biol. Res. 51:4. doi: 10.1186/s40659-018-0152-0

Kärkönen, A., and Kuchitsu, K. (2015). Reactive oxygen species in cell wall metabolism and development in plants. Phytochemistry 112, 22-32. doi: 10. 1016/j.phytochem.2014.09.016

Khositseth, S., Charngkaew, K., Boonkrai, C., Somparn, P., Uawithya, P., Chomanee, N., et al. (2017). Hypercalcemia induces targeted autophagic degradation of aquaporin-2 at the onset of nephrogenic diabetes insipidus. Kidney Int. 91, 1070-1087. doi: 10.1016/j.kint.2016.12.005

Kikuchi, Y., Hijikata, N., Ohtomo, R., Handa, Y., Kawaguchi, M., Saito, K., et al. (2016). Aquaporin-mediated long-distance polyphosphate translocation directed towards the host in arbuscular mycorrhizal symbiosis: application of virus-induced gene silencing. New Phytol. 211, 1202-1208. doi: 10.1111/nph. 14016

Kim, S. G., Kim, S. T., Wang, Y., Yu, S., Choi, I. S., Kim, Y. C., et al. (2011). The RNase activity of rice probenazole-induced protein 1 (PBZ1) plays a key role in cell death in plants. Mol. Cells 31, 25-31. doi: 10.1007/s10059-011-0004-z

Kirscht, A., Kaptan, S. S., Bienert, G. P., Chaumont, F., Nissen, P., de Groot, B. L., et al. (2016). Crystal structure of an ammonia-permeable aquaporin. PLoS Biol. 14:e1002411. doi: 10.1371/journal.pbio.1002411

Koraimann, G. (2003). Lytic transglycosylases in macromolecular transport systems of Gram-negative bacteria. Cell. Mol. Life Sci. 60, 2371-2388. doi: 10.1007/s00018-003-3056-1

Kreida, S., and Törnroth-Horsefield, S. (2015). Structural insights into aquaporin selectivity and regulation. Curr. Opin. Struct. Biol. 33, 126-134. doi: 10.1016/j. sbi.2015.08.004

Krinke, O., Ruelland, E., Valentová, O., Vergnolle, C., Renou, J. P., Taconnat, L., et al. (2007). Phosphatidylinositol 4-kinase activation is an early response to salicylic acid in Arabidopsis suspension cells. Plant Physiol. 144, 1347-1359. doi: $10.1104 /$ pp.107.100842

Kukulski, W., Schenk, A. D., Johanson, U., Braun, T., de Groot, B. L., Fotiadis, D., et al. (2005). The $5 \AA$ structure of heterologously expressed plant aquaporin SoPIP2;1. J. Mol. Biol. 350, 611-616. doi: 10.1016/j.jmb.2005.05.001

Kvitko, B. H., Ramos, A. R., Morello, J. E., Oh, H. S., and Collmer, A. (2007). Identification of harpins in Pseudomonas syringae pv. tomato DC3000, which are functionally similar to HrpK1 in promoting translocation of type III secretion system effectors. J. Bacteriol. 189, 8059-8072. doi: 10.1128/JB. 01146-07

Laliberté, J. F., and Sanfaçon, H. (2010). Cellular remodeling during plant virus infection. Annu. Rev. Phytopathol. 48, 69-91. doi: 10.1146/annurev-phyto073009-114239

Laloux, T., Junqueira, B., Maistriaux, L. C., Ahmed, J., Jurkiewicz, A., and François Chaumont, F. (2018). Plant and mammal aquaporins: same but different. Intl. J. Mol. Sci. 19:E521. doi: 10.3390/ijms19020521

Lee, A. H., Hurley, B., Felsensteiner, C., Yea, C., Ckurshumova, W., Bartetzko, V., et al. (2012). A bacterial acetyltransferase destroys plant microtubule networks and blocks secretion. PLoS Pathog. 8:e1002523. doi: 10.1371/journal. ppat.1002523

Lee, J., Klessig, D., and Nurnberger, T. (2001a). A harpin binding site in tobacco plasma membranes mediates activation of the pathogenesis related gene HIN1 independent of extracellular calcium but dependent on mitogen-activated protein kinase activity. Plant Cell 13, 1079-1093. doi: 10.1105/tpc.13.5.1079

Lee, J., Klusener, B., Tsiamis, G., Stevens, C., Neyt, C., Tampakaki, A. P., et al. (2001b). HrpZ $Z_{P s p h}$ from the plant pathogen Pseudomonas syringae pv. phaseolicola binds to lipid bilayers and forms an ion-conducting pore in vitro. Proc. Natl. Acad. Sci. U.S.A. 98, 289-294. doi: 10.1073/pnas.011265298

Lehman, T. A., Smertenko, A., and Sanguinet, K. A. (2017). Auxin, microtubules, and vesicle trafficking: conspirators behind the cell wall. J. Exp. Bot. 68, 33213329. doi: 10.1093/jxb/erx205 
Levine, A., Tenhaken, R., Dixon, R., and Lamb, C. (1994). $\mathrm{H}_{2} \mathrm{O}_{2}$ from the oxidative burst orchestrates the plant hypersensitive disease resistance response. Cell 79, 583-593. doi: 10.1016/0092-8674(94)90544-4

Li, C., and Wang, W. (2017). Molecular biology of aquaporins. Adv. Exp. Med. Biol. 969, 1-34. doi: 10.1007/978-94-024-1057-0_1

Li, L., Wang, H., Gago, J., Cui, H., Qian, Z., Kodama, N., et al. (2015). Harpin Hpal interacts with aquaporin PIP1;4 to promote the substrate transport and photosynthesis in Arabidopsis. Sci. Rep. 10:1038. doi: 10.1038/srep17207

Li, P., Zhang, L., Mo, X., Ji, H., Bian, H., Hu, Y., et al. (2019). Aquaporin PIP1;3 of rice and harpin $\mathrm{Hpal}$ of bacterial blight pathogen cooperate in a type III effector translocation. J. Exp. Bot. doi: 10.1093/jxb/erz130 [Epub ahead of print].

Li, X., Han, B., Xu, M., Han, L., Zhao, Y., Dong, H., et al. (2014). Plant growth enhancement and associated physiological responses are coregulated by ethylene and gibberellin in response to harpin protein Hpal. Planta 239, 831-846. doi: 10.1007/s00425-013-2013-y

Li, X., Han, L., Zhao, Y., You, Z., Dong, H., and Zhang, C. (2013). Harpin Hpal needs nitroxyl terminus to promote vegetative growth and leaf photosynthesis in Arabidopsis. J. Biosci. 39, 127-137. doi: 10.1007/s12038-013-9408-6

Li, Y. R., Che, Y. Z., Zou, H. S., Cui, Y. P., Guo, W., Zou, L. F., et al. (2011). $\mathrm{Hpa} 2$ required by $\mathrm{HrpF}$ to translocate Xanthomonas oryzae transcriptional activator-like effectors into rice for pathogenicity. Appl. Environ. Microbiol. 77, 3809-3818. doi: 10.1128/AEM.02849-10

Liu, Y., and He, C. (2016). Regulation of plant reactive oxygen species (ROS) in stress responses: learning from AtRBOHD. Plant Cell Rep. 35, 995-1007. doi: 10.1007/s00299-016-1950-x

Loque, D., Ludewig, U., Yuan, L., and von Wiren, N. (2005). Tonoplast intrinsic proteins AtTIP2;1 and AtTIP2;3 facilitate $\mathrm{NH}_{3}$ transport into the vacuole. Plant Physiol. 137, 671-680. doi: 10.1104/pp.104.051268

Lü, B. B., Sun, W. W., Zhang, S. P., Zhang, C. L., Qian, J., Wang, X. M., et al. (2011). $\mathrm{HrpN}_{\mathrm{Ea}}$-induced deterrent effect on phloem feeding of the green peach aphid Myzus persicae requires AtGSL5 and AtMYB44 genes in Arabidopsis thaliana. J. Biosci. 36, 123-137. doi: 10.1007/s12038-011-9016-2

Lu, H. A., Sun, T. X., Matsuzaki, T., Yi, X. H., Eswara, J., Bouley, R., et al. (2007). Heat shock protein 70 interacts with aquaporin-2 and regulates its trafficking. J. Biol. Chem. 282, 28721-28732. doi: 10.1074/jbc.M611101200

Maurel, C. (2007). Plant aquaporins: novel functions and regulation properties. FEBS Lett. 581, 2227-2236. doi: 10.1016/j.febslet.2007.03.021

Maurel, C., Boursiac, Y., Luu, D.-T., Santoni, V., Shahzad, Z., and Verdoucq, L. (2015). Aquaporins in plants. Phsiol. Rev. 95, 1321-1358. doi: 10.1152/physrev. 00008.2015

Maurel, C., and Plassard, C. (2011). Aquaporins: for more than water at the plantfungus interface? New Phytol. 190, 815-817. doi: 10.1111/j.1469-8137.2011. 03731.x

Maurel, C., Reizer, J., Schroeder, J. I., and Chrispeels, M. J. (1993). The vacuolar membrane protein $\gamma$-TIP creates water specific channels in Xenopus oocytes. EMBO. J. 12, 2241-2247. doi: 10.1002/j.1460-2075.1993.tb05877.x

Maurel, C., Verdoucqm, L., Luu, D. T., and Santoni, V. (2008). Plant aquaporins: membrane channels with multiple integrated functions. Annu. Rev. Plant Biol. 59, 595-624. doi: 10.1146/annurev.arplant.59.032607.092734

Melo, E. P., Lopes, C., Gollwitzer, P., Lortz, S., Lenzen, S., Mehmeti, I., et al. (2017). TriPer, an optical probe tuned to the endoplasmic reticulum tracks changes in luminal $\mathrm{H}_{2} \mathrm{O}_{2}$. BMC Plant Biol. 15:24. doi: 10.1186/s12915-017-0367-5

Miller, E. W., Dickinson, B. C., and Chang, C. J. (2010). Aquaporin-3 mediates hydrogen peroxide uptake to regulate downstream intracellular signaling. Proc. Natl. Acad. Sci. U.S.A. 107, 1568-15686. doi: 10.1073/pnas. 1005776107

Mueller, C. A., Broz, P., and Cornelis, G. R. (2008). The type III secretion system tip complex and translocon. Mol. Microbiol. 68, 1085-1095. doi: 10.1111/j.13652958.2008.06237.x

Mushegian, A. R., Fullner, K. J., Koonin, E. V., and Nester, E. W. (1996). A family of lysozyme-like virulence factors in bacterial pathogens of plants and animals. Proc. Natl. Acad. Sci. U.S.A. 93, 7321-7326. doi: 10.1073/pnas.93.14.7321

Nesverova, V., and Törnroth-Horsefield, S. (2019). Phosphorylation-dependent regulation of mammalian aquaporins. Cells 8:E82. doi: 10.3390/cells 8020082

Noël, L., Thieme, F., Nennstiel, D., and Bonas, U. (2002). Two novel type IIIsecreted proteins of Xanthomonas campestris pv. vesicatoria are encoded within the Hrp pathogenicity island. J. Bacteriol. 184, 1340-1348. doi: 10.1128/jb.184. $5.1340-1348.2002$
Nomura, K., Mecey, C., Lee, Y. N., Imboden, L. A., Chang, J. H., and He, S. Y. (2011). Effector-triggered immunity blocks pathogen degradation of an immunity-associated vesicle traffic regulator in Arabidopsis. Proc. Natl. Acad. Sci. U.S.A. 108, 10774-10779. doi: 10.1073/pnas.1103338108

Obacz, J., Avril, T., Le Reste, P. J., Urra, H., Quillien, V., Hetz, C., et al. (2017). Endoplasmic reticulum proteostasis in glioblastoma-From molecular mechanisms to therapeutic perspectives. Sci. Signal. 10:eaal2323. doi: 10.1126/ scisignal.aal 2323

Oh, C., and Beer, S. (2007). AtHIPM, an ortholog of the apple HrpN-interacting protein, is a negative regulator of plant growth and mediates the growthenhancing effect of HrpN in Arabidopsis. Plant Physiol. 145, 426-436. doi: 10.1104/pp.107.103432

Oh, H. S., and Collmer, A. (2005). Basal resistance against bacteria in Nicotiana benthamiana leaves is accompanied by reduced vascular staining and suppressed by multiple Pseudomonas syringae type III secretion system effector proteins. Plant J. 42, 348-359. doi: 10.1111/j.1365-313X.2005.02529.x

Otto, B., Uehlein, N., Sdorra, S., Fischer, M., Ayaz, M., Belastegui-Macadam, X., et al. (2010). Aquaporin tetramer composition modifies the function of tobacco aquaporins. J. Biol. Chem. 285, 31253-31260. doi: 10.1074/jbc.M110.115881

Pawłowicz, I., and Masajada, K. (2019). Aquaporins as a link between water relations and photosynthetic pathway in abiotic stress tolerance in plants. Gene 687, 166-172. doi: 10.1016/j.gene.2018.11.031

Pawłowicz, I., Waśkiewicz, A., Perlikowski, D., Rapacz, M., Ratajczak, D., Kosmala, A. (2018). Remodeling of chloroplast proteome under salinity affects salt tolerance of Festuca arundinacea. Photosynth. Res. 137, 475-492. doi: 10. 1007/s11120-018-0527-7

Péret, B., Li, G., Zhao, J., Band, L. R., Voß, U., Postaire, O., et al. (2012). Auxin regulates aquaporin function to facilitate lateral root emergence. Nat. Cell Biol. 4, 991-998. doi: 10.1038/ncb2573

Péret, B., Middleton, A. M., French, A. P., Larrieu, A., Bishopp, A., Njo, M., et al. (2013). Sequential induction of auxin efflux and influx carriers regulates lateral root emergence. Mol. Syst. Biol. 9:699. doi: 10.1038/msb.2013.43

Piscatelli, H. L., Li, M., and Zhou, D. (2016). Dual 4- and 5-phosphatase activities regulate SopB-dependent phosphoinositide dynamics to promote bacterial entry. Cell. Microbiol. 18, 705-719. doi: 10.1111/cmi.12542

Pitzschke, A. (2015). Modes of MAPK substrate recognition and control. Trends Plant Sci. 20, 49-55. doi: 10.1016/j.tplants.2014.09.006

Prado, K., Boursiac, Y., Tournaire-Roux, C., Monneuse, J. M., Postair, O., Da Ines, O., et al. (2013). Regulation of Arabidopsis leaf hydraulics involves lightdependent phosphorylation of aquaporins in veins. Plant Cell 25, 1029-1039. doi: $10.1105 /$ tpc.112.108456

Prasad, S., Xu, J., Zhang, Y., and Wang, N. (2016). SEC-translocon dependent extracytoplasmic proteins of Candidatus Liberibacter asiaticus. Front. Microbiol. 7:1989. doi: 10.3389/fmicb.2016.01989

Preston, G. M., and Agre, P. (1991). Isolation of the cDNA for erythrocyte integral membrane protein of 28 kilodaltons: member of an ancient channel family. Proc. Natl. Acad. Sci. U.S.A. 88, 11110-11114. doi: 10.1073/pnas.88.24.11110

Preston, G. M., Carroll, T. P., Guggino, W. B., and Agre, P. (1992). Appearance of water channels in Xenopus oocytes expressing red cell CHIP28 protein. Science 256, 385-387. doi: 10.1126/science.256.5055.385

Rey, T., and Jacquet, C. (2018). Symbiosis genes for immunity and vice versa. Curr. Opin. Plant Biol. 44, 64-71. doi: 10.1016/j.pbi.2018.02.010

Roche, J. V., and Törnroth-Horsefield, S. (2017). Aquaporin protein-protein interactions. Int. J. Mol. Sci. 18:E2255. doi: 10.3390/ijms18112255

Rodrigues, O., Reshetnyak, G., Grondin, A., Saijo, Y., Leonhardt, N., Maurel, C., et al. (2017). Aquaporins facilitate hydrogen peroxide entry into guard cells to mediate ABA- and pathogen-triggered stomatal closure. Proc. Natl. Acad. Sci. U.S.A. 114, 9200-9205. doi: 10.1073/pnas.1704754114

Ruiz-Lozano, J. M., and Aroca, R. (2017). "Plant aquaporins and mycorrhizae: their regulation and involvement in plant physiology and performance," in Plant Aquaporins: From Transport to Signaling, eds F. Chaumont and S. D. Tyerman (Cham: Springer International Publishing), 333-353. doi: 10.1007/978-3-31949395-4_15

Ruiz-Lozano, J. M., Aroca, R., Zamarreño, A. M., Molina, S., Andreo-Jiménez, B., Porcel, R., et al. (2016). Arbuscular mycorrhizal symbiosis induces strigolactone biosynthesis under drought and improves drought tolerance in lettuce and tomato. Plant Cell Environ. 39, 441-452. doi: 10.1111/pce.12631 
Rüter, C., Buss, C., Scharnert, J., Heusipp, G., and Schmidt, M. A. (2010). A newly identified bacterial cell-penetrating peptide that reduces the transcription of pro-inflammatory cytokines. J. Cell Sci. 123, 2190-2198. doi: 10.1242/jcs. 063016

Rüter, C., and Schmidt, M. A. (2017). Cell-penetrating bacterial effector proteins: better tools than targets. Trends Biotechnol. 35, 109-120. doi: 10.1016/j.tibtech. 2016.08.002

Sagi, M., and Fluhr, R. (2006). Production of reactive oxygen species by plant NADPH oxidases. Plant Physiol. 141, 336-340. doi: 10.1104/pp.106.078089

Sánchez-Romera, B., Ruiz-Lozano, J. M., Zamarreño, Á. M., García-Mina, J. M., and Aroca, R. (2016). Arbuscular mycorrhizal symbiosis and methyl jasmonate avoid the inhibition of root hydraulic conductivity caused by drought. Mycorrhiza 26, 111-122. doi: 10.1007/s00572-015-0650-7

Sang, S., Li, X., Gao, R., You, Z., Lü, B., Liu, P., et al. (2012). Apoplastic and cytoplasmic location of harpin protein $\mathrm{Hpal}_{\text {Xoo }}$ plays different roles in $\mathrm{H}_{2} \mathrm{O}_{2}$ generation and pathogen resistance in Arabidopsis. Plant Mol. Biol. 79, 375-391. doi: $10.1007 /$ s11103-012-9918-x

Santi-Rocca, J., and Blanchard, N. (2017). Membrane trafficking and remodeling at the host-parasite interface. Curr. Opin. Microbiol. 40, 145-151. doi: 10.1016/j. mib.2017.11.013

Sawa, T., Katoh, H., and Yasumoto, H. (2014). V-antigen homologs in pathogenic gram-negative bacteria. Microbiol. Immunol. 58, 267-285. doi: 10.1111/13480421.12147

Scharnert, J., Greune, L., Zeuschner, D., Lubos, M. L., Alexander Schmidt, M., and Rüter, C. (2013). Autonomous translocation and intracellular trafficking of the cell-penetrating and immune-suppressive effector protein YopM. Cell. Mol. Life Sci. 70, 4809-4823. doi: 10.1007/s00018-013-1413-2

Scheibner, F., Marillonnet, S., and Büttner, D. (2017). The TAL effector AvrBs3 from Xanthomonas campestris pv. vesicatoria contains multiple export signals and can enter plant cells in the absence of the type III secretion translocon. Front. Microbiol. 8:2180. doi: 10.3389/fmicb.2017.02180

Schreiber, K. J., Baudin, M., Hassan, J. A., and Lewis, J. D. (2016). Die another day: molecular mechanisms of effector-triggered immunity elicited by type III secreted effector proteins. Semin. Cell Dev. Biol. 56, 124-133. doi: 10.1016/j. semcdb.2016.05.001

Schwartz, A. R., Morbitzer, R., Lahaye, T., and Staskawicz, B. J. (2017). TALEinduced bHLH transcription factors that activate a pectate lyase contribute to water soaking in bacterial spot of tomato. Proc. Natl. Acad. Sci. U.S.A. 114, E897-E903. doi: 10.1073/pnas.1620407114

Shanmugam, S. K., and Dalbey, R. E. (2019). The conserved role of YidC in membrane protein biogenesis. Microbiol. Spectr. 7:PSIB-0014-2018. doi: 10. 1128/microbiolspec.PSIB-0014-2018

Shen, M., Bao, L. Z., Zheng, X., Zhao, X. X., and Guo, Z. F. (2019). Obestatin downregulating aquaporin 2 plasma membrane distribution through a shortterm regulatory effect. Am. J. Med. Sci. 357, 247-254. doi: 10.1016/j.amjms.2018. 12.010

Skrzypek, E., Cowan, C., and Straley, S. C. (1998). Targeting of the Yersinia pestis YopM protein into HeLa cells and intracellular trafficking to the nucleus. Mol. Microbiol. 30, 1051-1065. doi: 10.1046/j.1365-2958.1998.01135.x

Smirnoff, N., and Arnaud, D. (2019). Hydrogen peroxide metabolism and functions in plants. New Phytol. 221, 1197-1214. doi: 10.1111/nph.15488

Spoel, S. H., Mou, Z., Tada, Y., Spivey, N. W., Genschik, P., and Dong, X. (2009). Proteasome-mediated turnover of the transcription coactivator NPR1 plays dual roles in regulating plant immunity. Cell 137, 860-872. doi: 10.1016/j.cell. 2009.03.038

Sugio, A., Yang, B., and White, F. F. (2005). Characterization of the $h r p F$ pathogenicity peninsula of Xanthomonas oryzae pv. oryzae. Mol. Plant Microbe Interact. 18, 546-554. doi: 10.1094/MPMI-18-0546

Sui, H., Han, B. G., Lee, J. K., Walian, P., and Jap, B. K. (2001). Structural basis of water-specific transport through the AQP1 water channel. Nature 414, 872-878. doi: $10.1038 / 414872$ a

Sutka, M., Amodeo, G., and Ozu, M. (2017). Plant and animal aquaporins crosstalk: what can be revealed from distinct perspectives. Biophys. Rev. 9, 545-562. doi: 10.1007/s12551-017-0313-3

Tada, Y., Spoel, S. H., Pajerowska-Mukhtar, K., Mou, Z., Song, J., Wang, C., et al. (2008). Plant immunity requires conformational charges of NPR1 via S-nitrosylation and thioredoxins. Science 321, 952-956. doi: 10.1126/science. 1156970
Tejeda-Dominguez, F., Huerta-Cantillo, J., Chavez-Dueñas, L., and NavarroGarcia, F. (2017). A novel mechanism for protein delivery by the type 3 secretion system for extracellularly secreted proteins. mBio 8:e0184-17. doi: 10.1128/mBio.00184- 17

Tian, D., Wang, J., Zeng, X., Gu, K., Qiu, C., Yang, X., et al. (2014). The rice TAL effector-dependent resistance protein Xa10 triggers cell death and calcium depletion in the endoplasmic reticulum. Plant Cell 26, 497-515. doi: 10.1105/ tpc.113.119255

Tian, S., Wang, X., Li, P., Wang, H., Ji, H., Xie, J., et al. (2016). Plant aquaporin AtPIP1;4 links apoplastic $\mathrm{H}_{2} \mathrm{O}_{2}$ induction to disease immunity pathways. Plant Physiol. 171, 1635-1650. doi: 10.1104/pp.15.01237

Törnroth-Horsefield, S., Hedfalk, K., Fischer, G., Lindkvist-Petersson, K., and Neutze, R. (2010). Structural insights into eukaryotic aquaporin regulation. FEBS Lett. 584, 2580-2588. doi: 10.1016/j.febslet.2010.04.037

Törnroth-Horsefield, S., Wang, Y., Hedfalk, K., Johanson, U., Karlsson, M., Tajkhorshid, E., et al. (2006). Structural mechanism of plant aquaporin gating. Nature 439, 688-694. doi: 10.1038/nature04316

Torres, M. A. (2009). ROS in biotic interactions. Physiol. Plant 139, 414-429. doi: 10.1111/j.1399-3054.2009.01326.x

Verdoucq, L., Grondin, A., and Maurel, C. (2008). Structure-function analysis of plant aquaporin AtPIP2;1 gating by divalent cations and protons. Biochem. J. 415, 409-416. doi: 10.1042/BJ20080275

Wagner, S., Grin, I., Malmsheimer, S., Singh, N., Torres-Vargas, C. E., and Westerhausen, S. (2018). Bacterial type III secretion systems: a complex device for the delivery of bacterial effector proteins into eukaryotic host cells. FEMS Microbiol. Lett. 365:fny201. doi: 10.1093/femsle/fny201

Wang, D., Wang, Y., Fu, M., Mu, S., Han, B., Ji, H., et al. (2014). Transgenic expression of the functional fragment $\mathrm{Hpal}_{10-42}$ of the harpin protein Hpal imparts enhanced resistance to powdery mildew in wheat. Plant Dis. 98 448-455. doi: 10.1094/PDIS-07-13-0687-RE

Wang, F., Wang, Y., Zhang, X., Zhang, W., Guo, S., and Jin, F. (2014). Recent progress of cell-penetrating peptides as new carriers for intracellular cargo delivery. J. Control. Release 174, 126-136. doi: 10.1016/j.jconrel.2013. 11.020

Wang, J., Tian, D., Gu, K., Yang, X., Wang, L., Zeng, X., et al. (2017). Induction of Xa10-like genes in rice cultivar Nipponbare confers disease resistance to rice bacterial blight. Mol. Plant Microbe Interact. 30, 466-477. doi: 10.1094/MPMI11-16-0229-R

Wang, R., Wang, M., Chen, K., Wang, S., Mur, L. A. J., and Guo, S. (2018). Exploring the roles of aquaporins in plant-microbe interactions. Cells 7:E267. doi: $10.3390 /$ cells7120267

Wang, X., Zhang, L., Ji, H., Mo, X., Li, P., Wang, J., et al. (2018). Hpal is a type III translocator in Xanthomonas oryzae pv. oryzae. BMC Microbiol. 18:105. doi: 10.1186/s12866-018-1251-3

Wang, Y., Cohen, J., Boron, W. F., Schulten, K., and Tajkhorshid, E. (2007). Exploring gas permeability of cellular membranes and membrane channels with molecular dynamics. J. Struct. Biol. 157, 534-544. doi: 10.1016/j.jsb.2006. 11.008

Wang, Y., Liu, R., Wang, Y. C., Liang, Y. C., Wu, X., Li, B., et al. (2009). Nicotiana tabacum TTG1 contributes to ParA1-induced signalling and cell death in leaf trichomes. J. Cell Sci. 122, 2673-2685. doi: 10.1242/jcs.049023

Weber, S. S., Ragaz, C., Reus, K., Nyfeler, Y., and Hilbi, H. (2006). Legionella pneumophila exploits $\mathrm{PI}(4) \mathrm{P}$ to anchor secreted effector proteins to the replicative vacuole. PLoS Pathog. 2:e46. doi: 10.1371/journal.ppat. 0020046

Wei, Z.-M., Lacy, R. J., Zumoff, C. H., Bauer, D. W., He, S. Y., Collmer, A., et al. (1992). Harpin, elicitor of the hypersensitive response produced by the plant pathogen Erwinia amylovora. Science 257, 85-88. doi: 10.1126/science.162 1099

White, F. F., Potnis, N., Jones, J. B., and Koebnik, R. (2009). The type III effectors of Xanthomonas. Mol. Plant Pathol. 10, 749-766. doi: 10.1111/j.1364-3703.2009. 00590.x

Wree, D., Wu, B., Zeuthen, T., and Beitz, E. (2011). Requirement for asparagine in the aquaporin NPA sequence signature motifs for cation exclusion. FEBS J. 278, 740-748. doi: 10.1111/j.1742-4658.2010.07993.x

Wudick, M. M., Li, X., Valentini, V., Geldner, N., Chory, J., Lin, J., et al. (2015). Subcellular redistribution of root aquaporins induced by hydrogen peroxide. Mol. Plant 8, 1103-1114. doi: 10.1016/j.molp.2015.02.017 
Wudick, M. M., Luu, D. T., and Maurel, C. (2009). A look inside: localization patterns and functions of intracellular plant aquaporins. New Phytol. 184, 289-302. doi: 10.1111/j.1469-8137.2009.02985.x

Xin, X. F., Nomura, K., Aung, K., Velásquez, A. C., Yao, J., Boutrot, F., et al. (2015). Bacteria establish an aqueous living space in plants crucial for virulence. Nature 539, 524-529. doi: 10.1038/nature20166

Xu, Y., Yao, H., Wang, Q., Xu, W., Liu, K., Zhang, J., et al. (2018). Aquaporin3 attenuates oxidative stress-induced nucleus pulposus cell apoptosis through regulating the p38 MAPK pathway. Cell. Physiol. Biochem. 50, 1687-1697. doi: $10.1159 / 000494788$

Yang, B. (2017). Advances in Experimental Medicine and Biology 969 Aquaporins. Dordrecht: Springer Science + Business Media B.V.

Yang, B., Sugio, A., and White, F. F. (2006). Os 8 N3 is a host disease-susceptibility gene for bacterial blight of rice. Proc. Natl. Acad. Sci. U.S.A. 103, 10503-10508. doi: 10.1073/pnas.0604088103

Zelazny, E., Miecielica, U., Borst, J. W., Hemminga, M. A., and Chaumont, F. (2009). An N-terminal diacidic motif is required for the trafficking of maize aquaporins ZmPIP2;4 and ZmPIP2;5 to the plasma membrane. Plant J. 57, 346-355. doi: 10.1111/j.1365-313X.2008.03691.x

Zhang, J., Shao, F., Li, Y., Cui, H., Chen, L., Li, H., et al. (2007). A Pseudomonas syringae effector inactivates MAPKs to suppress PAMP-induced immunity in plants. Cell Host Microbe 17, 175-185. doi: 10.1016/j.chom.2007.03.006

Zhang, J., Wang, X., Zhang, Y., Zhang, G., and Wang, J. (2008). A conserved Hpa2 protein has lytic activity against the bacterial cell wall in phytopathogenic Xanthomonas oryzae. Appl. Microbiol. Biotechnol. 79, 605-616. doi: 10.1007/ s00253-008-1457-7

Zhang, L., Hu, Y., Li, P., Wang, X., and Dong, H. (2018). Silencing of an aquaporin gene diminishes bacterial blight disease in rice. Aust. Plant Pathol. 48, 143-158. doi: 10.1007/s13313-018-0609-1
Zhang, S., Feng, M., Chen, W., Zhou, X., Lu, J., Wang, Y., et al. (2019). In rose, transcription factor PTM balances growth and drought survival via PIP2;1 aquaporin. Nat. Plants 5, 290-299. doi: 10.1038/s41477-019-0376-1

Zhao, Y. Y., Li, C., Ge, J., Xu, M. Y., Zhu, Q., Wu, T. Q., et al. (2014). Recessive mutation identifies auxin-repressed protein ARP1 that regulates growth and disease resistance in tobacco. Mol. Plant Microbe Interact. 27, 638-654. doi: 10.1094/MPMI-08-13-0250-R

Zhou, H., Morgan, R. L., Guttman, D. S., and Ma, W. (2009). Allelic variants of the Pseudomonas syringae type III effector HopZ1 are differentially recognized by plant resistance systems. Mol. Plant Microbe Interact. 22, 176-189. doi: 10.1094/MPMI-22-2-0176

Zhu, W., MaGbanua, M. M., and White, F. F. (2000). Identification of two novel Hrp-associated genes in the Hrp gene cluster of Xanthomonas oryzae pv. oryzae. J. Bacteriol. 182, 1844-1853. doi: 10.1128/jb.182.7.1844-1853. 2000

Zipfel, C., Robatzek, S., Navarro, L., Oakeley, E. J., Jones, J. D., Felix, G., et al. (2004). Bacterial disease resistance in Arabidopsis through flagellin perception. Nature 428, 764-767. doi: 10.1038/nature02485

Conflict of Interest Statement: The authors declare that the research was conducted in the absence of any commercial or financial relationships that could be construed as a potential conflict of interest.

Copyright (c) 2019 Zhang, Chen and Dong. This is an open-access article distributed under the terms of the Creative Commons Attribution License (CC BY). The use, distribution or reproduction in other forums is permitted, provided the original author(s) and the copyright owner(s) are credited and that the original publication in this journal is cited, in accordance with accepted academic practice. No use, distribution or reproduction is permitted which does not comply with these terms. 